\title{
TGF- $\beta$ downregulation-induced cancer cell death is finely regulated by the SAPK signaling cascade
}

\author{
Zhezhu Han ${ }^{1,2}$, Dongxu Kang ${ }^{1,2}$, Yeonsoo Joo ${ }^{1,3}$, Jihyun Lee ${ }^{1,3}$, Geun-Hyeok Oh ${ }^{1,3}$, Soojin Choi ${ }^{1,3}$, Suwan Ko ${ }^{1,3}$, \\ Suyeon Je${ }^{1}$, Hye Jin Choi ${ }^{4}$ and Jae J. Song ${ }^{1,3}$
}

\begin{abstract}
Transforming growth factor (TGF)- $\beta$ signaling is increasingly recognized as a key driver in cancer. In progressive cancer tissues, TGF- $\beta$ promotes tumor formation, and its increased expression often correlates with cancer malignancy. In this study, we utilized adenoviruses expressing short hairpin RNAs against TGF- $\beta 1$ and TGF- $\beta 2$ to investigate the role of TGF- $\beta$ downregulation in cancer cell death. We found that the downregulation of TGF- $\beta$ increased the phosphorylation of several SAPKs, such as p38 and JNK. Moreover, reactive oxygen species (ROS) production was also increased by TGF- $\beta$ downregulation, which triggered Akt inactivation and NOX4 increase-derived ROS in a cancer celltype-specific manner. We also revealed the possibility of substantial gene fluctuation in response to TGF- $\beta$ downregulation related to SAPKs. The expression levels of Trx and GSTM1, which encode inhibitory proteins that bind to ASK1, were reduced, likely a result of the altered translocation of Smad complex proteins rather than from ROS production. Instead, both ROS and ROS-mediated ER stress were responsible for the decrease in interactions between ASK1 and Trx or GSTM1. Through these pathways, ASK1 was activated and induced cytotoxic tumor cell death via p38/ JNK activation and (or) induction of ER stress.
\end{abstract}

\section{Introduction}

The transforming growth factor (TGF) superfamily comprises three isoforms of multifunctional cytokines (namely, $\beta 1, \beta 2$, and $\beta 3$ ) that regulate numerous cellular and biological functions, including cell proliferation, apoptosis, differentiation, and migration; embryonic patterning; stem cell maintenance; immune regulation; bone formation; and tissue remodeling and repair ${ }^{1-3}$. The wide variety of TGF- $\beta$ functions is highly cell-type specific and context dependent ${ }^{1,4}$. For example, TGF- $\beta$ acts as a tumor suppressor in normal and early cancer cells by promoting apoptosis over proliferation, thus hindering

Correspondence: Hye Jin Choi (choihj@yuhs.ac)

Jae J. Song (jjs109@yuhs.ac)

${ }^{1}$ Institute for Cancer Research, Yonsei University College of Medicine, Seoul, Korea

${ }^{2}$ Department of Oncology, Affiliated Hospital of Yanbian University, Yanji, Jilin Province, P.R. China

Full list of author information is available at the end of the article. immortalization ${ }^{5}$. On the other hand, it also promotes tumor metastasis by stimulating the epithelial-mesenchymal transition, chemoattraction, migration, invasion, and cell adhesion ${ }^{6-10}$. The mechanisms by which TGF- $\beta$ inhibits cell proliferation while promoting cell growth and enhancing both stem cell pluripotency and differentiation remain an enigma ${ }^{11-13}$.

TGF- $\beta$ binds to two types of serine/threonine kinase receptors $^{14}$, type I and type II, which form heteromeric cell surface complexes that stimulate the canonical (Smad-dependent) signaling pathway ${ }^{10}$. Activation of type I receptors leads to C-terminal phosphorylation of Smad2 and Smad3, which then dissociate and form a heterotrimeric complex with Smad4 ${ }^{15,16}$. This complex then translocates to the nucleus to regulate target gene expression $^{17,18}$. TGF- $\beta$ can also stimulate Smadindependent signaling pathways, which involve the activation of small GTP-binding protein $\mathrm{Rho}^{19}$, 
phosphatidylinositol 3-kinase (PI3K)-Akt ${ }^{20-22}$, and TGF$\beta$-activated kinase 1 (TAK1) $^{23}$, as well as Ras-extracellular signal-regulated kinase (ERK), c-Jun N-terminal kinase (JNK), and p38 stress-activated protein kinase (SAPK) ${ }^{24-}$ 26 .

JNK and p38 are also activated by apoptosis signalregulating kinase 1 (ASK1), a mitogen-activated protein kinase (MAPK) kinase kinase ${ }^{27,28}$. However, the roles of JNK and p38 signaling pathways during apoptosis have been controversial depending on the duration or strength of the signals ${ }^{29,30}$. The activation of ASK1 is mainly triggered under cytotoxic stresses by the tumor necrosis factor Fas and reactive oxygen species (ROS) $)^{28,31-33}$.

ROS are formed as a natural by-product of oxygen metabolism $^{34}$. Large amounts of ROS are produced via multiple mechanisms, depending on the cell and tissue type $^{35}$. Elevated levels of ROS have been detected in almost all cancers, in which they promote many aspects of tumor development and progression ${ }^{36}$. However, ROS can induce cancer cell apoptosis as well as senescence ${ }^{36}$. Additionally, low doses of hydrogen peroxide and superoxide have been shown to stimulate cell proliferation in a wide variety of cancer cell types ${ }^{37}$. Recently, it was shown that ROS can trigger endoplasmic reticulum (ER) stress or vice versa in vivo and in vitro ${ }^{38,39}$. Under prolonged and severe ER stress, the unfolded protein response (UPR) can become cytotoxic. Among the UPR signaling pathways, inositol-requiring enzyme $1 \alpha$ (IRE1 $\alpha)$ and protein kinase RNA-like kinase (PERK) are predominantly represented as sensors of ER stress ${ }^{40,41}$. Likewise, oxidative stresssensing redox proteins such as thioredoxin (Trx) play a role in many important biological processes, including redox signaling ${ }^{42}$. Trx has antiapoptotic effects, including a direct inhibitory interaction with ASK $1^{43}$. The redox state-dependent association and dissociation of Trx with ASK1 lead to MAPK activation-induced apoptosis ${ }^{44}$. The activity of ASK1 is also suppressed by glutathione $S$ transferase $\mathrm{Mu} 1$ (GSTM1), an enzyme involved in the metabolism of drugs and xenobiotics ${ }^{45}$. Similar to Trx, GSTM1 protects cells from a variety of stresses, including oxidative stress ${ }^{45}$.

In this study, we designed adenoviruses to deliver short hairpin RNAs (shRNAs) for TGF- $\beta 1$ or TGF- $\beta 2$ and found that downregulation of TGF- $\beta 1$ or TGF- $\beta 2$ leads to tumor cell death by inducing ASK1 activation and p38 and JNK phosphorylation through an ER stress/ROSescalated positive feedback circuit.

\section{Materials and methods Cell culture}

Human A549 (lung adenocarcinoma), U251N (glioblastoma), DU-145 (prostate cancer), Huh-7 (hepatocarcinoma), MDA-MB-231 (breast carcinoma), MDA-MB-231Her2 (Her2-stably transfected breast carcinoma), SK-Hep1 (hepatocarcinoma), A375 (melanoma), HPAC (pancreas adenocarcinoma), MiaPaCa-2 (pancreas adenocarcinoma), and human embryonic kidney 293A cells were cultured in Dulbecco's modified Eagle's medium (DMEM, HyClone, Logan, UT, USA) containing 10\% fetal bovine serum (FBS, HyClone, Logan, UT, USA). Human normal pancreatic cells (Applied Biological Materials, Canada) were cultured in Prigrow II medium containing 10\% FBS. Cells were maintained in a $37^{\circ} \mathrm{C}$ humidified atmosphere containing $5 \%$ $\mathrm{CO}_{2}$.

\section{Reagents}

Small interfering RNAs (siRNAs) for NOX4, NOX1, Smad4, and ASK1 and antibodies against glyceraldehyde 3-phosphate dehydrogenase, phospho-HSP27 (Ser78), HSP27, Trx, GSTM1, AP1, SP1, Smad4, ASK1, and phospho-ASK1 (Thr845) were purchased from Santa Cruz Biotechnology (Santa Cruz, CA, USA). Antibodies against p38, phospho-p38 (Thr180/Tyr182), phosphoERK (Thr202/Tyr204), phospho-src (Tyr416), phosphoAkt (Ser473), phospho-stat3 (Tyr705), phospho-p65 (Ser536), phospho-JNK (Thr183/Tyr185), phosphoSmad2 (Ser465/467), phospho-Smad3 (Ser423/425), Smad2, Smad3, p65, ERK, Akt, stat3, JNK, src, BIP, Calnexin, Ero1-L $\alpha$, CHOP, PERK, and PDI were purchased from Cell Signaling Technology (Beverly, MA, USA). Phospho-IRE1 $\alpha$ was purchased from Thermo Fisher Scientific (Waltham, MA, USA). Peroxiredoxin (Prx) was purchased from Abfrontier (Seoul, Korea). Glutaredoxin (Grx) was purchased from Novus Biologicals (Littleton, CO, USA). Recombinant human TGF- $\beta 1$ and TGF- $\beta 2$ were purchased from R\&D Systems (Minneapolis, MN, USA). SB203580 was purchased from EMD Millipore (Billerica, MA, USA), and GKT137831 was purchased from ApexBio (Houston, TX, USA). All other chemicals were purchased from Sigma-Aldrich (St. Louis, MO, USA).

\section{Construction of shuttle vectors expressing human TGF- $\beta 1$ and TGF- $\beta 2$ shRNA}

The detailed construction of human TGF- $\beta 1$ and TGF$\beta 2$ shRNA was described in $\mathrm{Oh}$ et $\mathrm{al}^{46}$. The target sequence of TGF- $\beta 1$ (5'-ACCAGAAATACAGCAACAA TTCCTG-3') was selected after validation among three candidate sequences (Suppl. Figure 1A). The target sequence of TGF- $\beta 2$ (5'-GGATTGAGCTATATCAGA TTCTCAA-3') was selected after validation among five candidate sequences (Supple. Figure 1B). To express human TGF- $\beta 1$ shRNA in adenovirus, the top strand sequence (5'-GATCCGCCAGAAATACAGCAACAATT CCTGTCTCTCCAGGAATTGTTGCTGTATTTCTGG TTTTTTTA-3') and the bottom strand sequence (5'-A GCTTAAAAAAACCAGAAA TACAGCAACAATTCC TGGAGAGACAGGAATTGTTGCTGTATTTCTGG 
TG-3') were annealed and subcloned into BamHI/HindIII-digested pSP72 $\triangle \mathrm{E} 3-\mathrm{U} 6 \mathrm{E} 3$ shuttle vector to generate pSP72 $\Delta$ E3-U6-shTGF- $\beta 1$. To express human TGF- $\beta 2$ shRNA in adenovirus, the top strand sequence (5'-G ATCCGGATTGAGCTATATCAGATTCTCAATCTCT TGAGAATCTGATATAGCTCAATCCTTTTA-3') and the bottom strand sequence (5'- AGCTTAAAAGGA TTGAGCTATATCAGATTCTCAAGAGATTGAGAAT CTGATATAGCTCAATCCG-3') were annealed and subcloned into BamHI/HindIII-digested pSP72 $\triangle \mathrm{E} 3-\mathrm{U} 6$ E3 shuttle vector to generate pSP72 $\Delta$ E3-U6-shTGF- $\beta 2$.

\section{Production of adenoviral vectors}

These vectors, named pSP72 $\Delta \mathrm{E} 3$-U6-shTGF- $\beta 1$ or pSP72 $\Delta$ E3-U6-shTGF- $\beta 2$, were linearized by $\mathrm{XmnI}$ digestion and co-transformed into Escherichia coli BJ5183 together with the SpeI-digested adenoviral vector (dl324IX) for homologous recombination. The recombined adenoviral plasmids dl324-IX- $\triangle \mathrm{E} 3-\mathrm{U} 6-\mathrm{NC}$, dl324-IX$\Delta$ E3-U6-shTGF- $\beta 1$, and dl324-IX- $\Delta$ E3-U6-shTGF- $\beta 2$ were then digested with PacI and transfected into 293A cells to generate replication-incompetent adenovirus (AdNC, Ad-shTGF- $\beta 1$, and Ad-shTGF- $\beta 2$ ).

\section{Names of the recombinant adenoviruses \\ Ad-NC, negative control adenovirus \\ Ad-shTGF- $\beta 1$, adenovirus expressing shRNA for human TGF- $\beta 1$ \\ Ad-shTGF- $\beta 2$, adenovirus expressing shRNA for human TGF- $\beta 2$}

\section{MTS viability assay}

The CellTiter $96^{\oplus}$ Aqueous Assay Kit (Promega, Madison, WI, USA) is composed of solutions of a novel tetrazolium compound (3-(4,5-dimethylthiazol-2-yl)-5-(3carboxymethoxyphenyl)-2-(4-sulfophenyl)-2H-tetrazolium, inner salt (MTS)) and an electron coupling reagent (phenazine ethosulfate). MTS is bioreduced by cells into a formazan product that is soluble in tissue culture media. After adenovirus (NC, shT1, shT2) infection at a multiplicity of infection (MOI) of 100 for $48 \mathrm{~h}$ to A375 or HPAC cell lines in 96-well plates, a total of $50 \mu \mathrm{L}$ of supernatant from each well was transferred into a new 96-well flat-bottom plate. The absorbance of the formazan at $490 \mathrm{~nm}$ was measured directly from 96-well assay plates without additional processing. The conversion of MTS into aqueous, soluble formazan is accomplished by dehydrogenase enzymes found in metabolically active cells. The quantity of formazan product as measured by the absorbance at $490 \mathrm{~nm}$ is directly proportional to the number of living cells in culture.

\section{Western blot analysis}

Cells were lysed with $1 \times$ Laemmli lysis buffer $(62.5 \mathrm{mM}$ Tris, $\mathrm{pH}$ 6.8, $2 \%$ sodium dodecyl sulfate, $10 \%$ glycerol,
$0.002 \%$ bromophenol blue), and the protein concentration was determined using a BCA Protein Assay Kit (Thermo Scientific, Fremont, CA, USA). Then protein samples were separated by sodium dodecyl sulfate-polyacrylamide gel electrophoresis (SDS-PAGE), and the gels were electro-transferred onto a polyvinylidene difluoride membrane (Millipore, Billerica, MA, USA). Each membrane was blocked with $5 \%$ nonfat dry milk in phosphatebuffered saline (PBS)-Tween-20 $(0.1 \%, \mathrm{v} / \mathrm{v})$ at room temperature for $1 \mathrm{~h}$. The membrane was then incubated with primary antibody (diluted according to the manufacturer's instructions) for $2 \mathrm{~h}$. Horseradish peroxidaseconjugated anti-rabbit or anti-mouse immunoglobulin G ( $\operatorname{IgG}$ ) was used as a secondary antibody. Immunoreactive proteins were visualized with a chemiluminescent detection kit (ELPIS biotech, Daejon, Korea). For imaging, a ChemiDoc system (Syngene, Frederick, MD, USA) was used.

\section{Real-time polymerase chain reaction (RT-PCR)}

After infection of adenovirus expressing shRNA for TGF- $\beta 1$ or $-\beta 2$ at an MOI of 100 , cells were lysed with Trizol reagent (Life Technologies, Carlsbad, CA, USA), and the total RNA was isolated using chloroform. The RNA concentration was determined using a Nanodrop 2000 (Thermo Scientific). The real-time PCR was performed using a Power SYBR Green RNA-to-CT 1-Step Kit (Life Technologies). The reaction mixture contained the reverse transcriptase enzyme mix, reverse transcription PCR mix, forward primer, reverse primer, RNA template, and nuclease-free water. Human TGF- $\beta 1$ cDNA was amplified using the forward primer 5'-T TGCTTCAGCTCCACAGAGA-3' and the reverse primer 5'-TGGTTGTAGAGGGCAAGGAC-3'. Human TGF- $\beta 2$ cDNA was amplified using the forward primer 5'-G TGAATGGCTCTCCTTCGAC-3' and the reverse primer 5'-CCTCGAGCTCTTCGCTTTTA-3'. Human NOX4 cDNA was amplified using the forward primer 5'- A GGAGAACCAGGAGATTGTTGGATAAA-3' and the reverse primer 5'- ATCTGAGGGATGACTTATGACCG AAAT-3'. Human $\beta$-actin was amplified using the forward primer 5'-GGCTGTATTCCCCTCCATCG-3' and the reverse primer 5'-CCAGTTGGTAACAATGCCATGT-3'.

\section{Microarray analyses}

cDNA microarray was performed using total RNA isolated from two different cancer cell lines after $48 \mathrm{~h}$ of infection with TGF- $\beta 1$ or $-\beta 2$ shRNA-expressing adenovirus. RNA was prepared using Trizol (Invitrogen LifeTechnologies). All cDNA microarray experiments, including cRNA labeling, hybridization to the Illumina expression bead-chip, scanning, and data analyses using Illumina GenomeStudiov2011.1, were performed by Macrogen Inc. (Seoul, Korea). 


\section{Clonogenic assay}

For survival determination, cells were plated on 6-well plates at $1 \times 10^{5}$ cells/well. After adenovirus (NC, shT1, shT2) infection at an MOI of 100 for $48 \mathrm{~h}$ in A375 or HPAC cell lines, cells were trypsinized and replated in the wells of 6-well plates at $5 \times 10^{3}$ or $1 \times 10^{4}$ cells/well. Then the cells were monitored daily by microscopy. When cells formed colonies, the remaining cells on the plate were fixed with $4 \%$ paraformaldehyde and stained with $0.5 \%$ crystal violet.

\section{Measurement of intracellular levels of ROS}

Intracellular ROS were assessed using the ROS-specific probe 2'-7'-diclorofluorescein diacetate (DCF-DA, SigmaAldrich, St. Louis, MO, USA). Cells were incubated with $20 \mu \mathrm{M}$ DCF-DA for $1 \mathrm{~h}$, and fluorescence signals were obtained with a fluorescence microscope (Olympus IX71).

\section{Enzyme-linked immunosorbent assay (ELISA)}

Cells were plated in the wells of 6 -well plates at $1 \times 10^{5}$ cells/well. After $48 \mathrm{~h}$, the supernatants were collected. The levels of secreted TGF- $\beta 1$ or TGF- $\beta 2$ were determined by ELISA according to the manufacturer's instructions (R\&D Systems, Minneapolis, MN, USA).

\section{Site-directed mutagenesis}

HA-tagged ASK1 wild type was constructed in the pCDNA3.1 plasmid (Invitrogen, Carlsbad, CA). A kinaseinactive form of ASK1 (K709M) was constructed from PCR using pcDNA3.1-HA-ASK1 as a template and the QuickChange II Site-Directed Mutagenesis Kit (Agilent Technologies, Santa Clara, SF, USA). The sense and antisense primers used were 5'-GCAACCAAGTCAGAATTGCTATTATGGAAATCCCAGAGAGAGAC-3' and 5'-GTCTCTCTCTGGGATTTCCATAATAGCAAT TCTGACTTGGTTGC-3', respectively, for K709M.

\section{Immunoprecipitation (IP)}

Co-IP procedures were performed at $4{ }^{\circ} \mathrm{C}$ unless otherwise indicated, using a Pierce spin column that can be capped and plugged with a bottom plug for incubation or unplugged to remove the supernatant by centrifugation at $1000 \times g$ for $1 \mathrm{~min}$. Binding of Trx, GSTM1, ASK1, AP1, SP1, or Smad4 antibody to protein A/G agarose was performed using the protocol described in Pierce crosslink IP kits with slight modification. Protein A/G agarose slurry $(20 \mu \mathrm{l})$ was washed twice with $200 \mu \mathrm{l}$ of PBS buffer and incubated with $100 \mu \mathrm{l}$ of Trx, GSTM1, ASK1, AP1, SP1, or Smad4 antibody prepared in PBS $(10 \mu \mathrm{l}$ of Trx, GSTM1, ASK1, AP1, SP1, or Smad4 antibody $+85 \mu \mathrm{l}$ of $\mathrm{H}_{2} \mathrm{O}+5 \mu \mathrm{l}$ of $20 \times \mathrm{PBS}$ ) at $25^{\circ} \mathrm{C}$ for $30 \mathrm{~min}$ on a mixer. In parallel, mouse or rabbit serum with the same concentration of IgG was similarly prepared as a negative control (NC). Then the supernatant was discarded, and the beads were washed three times with $300 \mu \mathrm{l}$ of PBS, followed by incubation with $50 \mu$ of disuccinimidyl suberate (DSS) solution $(2.5 \mu \mathrm{l}$ of $20 \times \mathrm{PBS}+38.5 \mu \mathrm{l}$ of $\mathrm{H}_{2} \mathrm{O}+2.5 \mathrm{mM}$ DSS in dimethyl sulfoxide) at $25^{\circ} \mathrm{C}$ for 45-60 min on a mixer. After removing the supernatant, the beads were washed three times with $50 \mu \mathrm{l}$ of $100 \mathrm{mM}$ glycine (pH 2.8), twice with $300 \mu \mathrm{l}$ of PBS buffer containing 1\% NP-40 and then once with $300 \mu \mathrm{l}$ of PBS. The antibody-crosslinked beads were incubated overnight at 4 ${ }^{\circ} \mathrm{C}$ with $600 \mu \mathrm{l}$ of lysate of A375 or HPAC cells that was pre-cleared with control agarose resin (Pierce) for $1 \mathrm{~h}$ on a shaker. After removing the supernatant (flow-through) and washing with $300 \mu \mathrm{l}$ of washing buffer $(25 \mathrm{mM}$ Tris, $150 \mathrm{mM} \mathrm{NaCl}, 1 \mathrm{mM}$ EDTA, 1\% NP-40, 5\% glycerol, $\mathrm{pH}$ 7.4) three times, the immunoprecipitates were eluted with $60 \mu \mathrm{l}$ of elution buffer and then boiled for $10 \mathrm{~min}$. The eluted complex was subjected to SDS-PAGE separation for western blotting.

\section{Chromatin IP assay (ChIP assay)}

The ChIP assay was performed using a kit from Thermo Scientific (Thermo Fisher Scientific, Waltham, USA) according to the manufacturer's instructions. Briefly, following treatment, cells were washed with PBS, crosslinked with $1 \%$ formaldehyde for $10 \mathrm{~min}$, rinsed with ice-cold PBS, collected into PBS containing protease inhibitors, and then resuspended in lysis buffer (1\% SDS, $10 \mathrm{mM}$ EDTA, $50 \mathrm{mM}$ Tris at $\mathrm{pH} 8.1$ with $1 \%$ protease inhibitor cocktail). After the cells were sonicated to produce 200-1000-bp DNA fragments, followed by centrifugation to remove insoluble material, IP was performed with the indicated antibodies overnight at $4{ }^{\circ} \mathrm{C}$ with mixing. Then $20 \mu \mathrm{L}$ of protein $\mathrm{A} / \mathrm{G}$ beads was added to each IP and incubated for $2 \mathrm{~h}$ at $4{ }^{\circ} \mathrm{C}$ with mixing. After removing the supernatant, the beads were washed twice with IP Wash Buffer 1, once with Wash Buffer 2, once with $150 \mu \mathrm{L}$ of $1 \times$ IP Elution Buffer, and then incubated at $65^{\circ} \mathrm{C}$ for $30 \mathrm{~min}$ with vigorous shaking. After dispensing the supernatant (containing the eluted protein-chromatin complex) into prepared tubes with $\mathrm{NaCl}$ and Proteinase $\mathrm{K}$ in a $65^{\circ} \mathrm{C}$ heat block for $1.5 \mathrm{~h}, 750 \mu \mathrm{L}$ of DNA Binding Buffer was added, and $500 \mu \mathrm{L}$ of each sample was removed into a DNA Clean-Up Column, which was inserted into a $2 \mathrm{~mL}$ collection tube. After removing the supernatant (flowthrough), the remaining sample was dispensed into the same DNA Clean-Up Column and washed once with Wash Buffer, and $50 \mu \mathrm{L}$ of DNA Column Elution Solution was added to the column. After centrifugation, the resulting solution was the purified DNA. RT-PCR was performed using primers specific for the human $\operatorname{Trx}$ promoter (5'-TCCAGGAGTCTGCCTCTGTTAG-3' and 5'-CTGCTGGA GTCTGACGAGCG-3') and the GSTM1 promoter (5'-TAGGATCTGGCTGGTGTCTC-3' and 5'GTGCGGATTCCGCAGACAGG-3'). PCR using 
Absolute qPCR SYBR Green Fluorescein Mix (Thermo Scientific) was performed as follows: 40 cycles of $95^{\circ} \mathrm{C}$ for $15 \mathrm{~s}$ and $62{ }^{\circ} \mathrm{C}$ for $1 \mathrm{~min}$, with an initial incubation at $95^{\circ} \mathrm{C}$ for $15 \mathrm{~min}$.

\section{Confocal immunofluorescence staining}

Cells were fixed with $4 \%$ formaldehyde for $15 \mathrm{~min}$ and then washed three times with PBS. After washing with PBS 3 times, the slides were incubated with $5 \%$ bovine serum albumin (BSA) for $1 \mathrm{~h}$. After blocking, the slides were incubated in primary antibody $(\operatorname{Smad} 4)$ at the appropriate dilution (1:100) in PBS for $12 \mathrm{~h}$ at $4{ }^{\circ} \mathrm{C}$ and then washed three times with PBS. After washing with PBS 3 times, the slides were incubated in Flamma 552conjugated secondary antibody (1:1000) (BioActs, Korea) in PBS for $1 \mathrm{~h}$ at room temperature and then washed three times with PBS. After washing with PBS 3 times, the slides were counterstained with DAPI-Fluoromount-G (Aviva, San Diego, USA) for $20 \mathrm{~min}$ at room temperature to stain nuclei and then coverslipped. Images were acquired using a confocal laser scanning microscope (Carl Zeiss, Jena, Germany).

\section{Nucleus/cytosol fractionation}

Cells were lysed with $0.5 \%$ Triton X-100 lysis buffer (50 $\mathrm{mM}$ Tris-HCI (pH 7.5), 0.5\% Triton X-100, $137.5 \mathrm{mM}$ $\mathrm{NaCI}, 10 \%$ glycerol, $1 \mathrm{mM}$ sodium vanadate, $5 \mathrm{mM}$ EDTA, and protease inhibitors $(1 \mathrm{mM}$ phenylmethanesulfonylfluoride)) on ice for $15 \mathrm{~min}$ and then centrifuged at $3000 \mathrm{rpm}$ for $5 \mathrm{~min}$. After centrifugation, the supernatant (membrane/cytoplasmic fraction) was transferred into a new microcentrifuge tube, and the nuclear pellets were rinsed with lysis buffer and centrifuged at 13,000 rpm for $15 \mathrm{~min}$. After centrifugation, the supernatants were transferred into a new microcentrifuge tube, and then an equal amount of $2 \times$ SDS-PAGE sample buffer was added to the tubes containing the nuclear and membrane/ cytoplasmic fractions. Both tubes were boiled for $10 \mathrm{~min}$, and each boiled sample was subjected to SDS-PAGE separation for western blotting.

\section{Animal study}

To generate a xenograft tumor model, $8 \times 10^{6}$ A375 or HPAC cells were injected into the subcutaneous abdominal region of male $\mathrm{BALB} / \mathrm{c}$ athymic nude mice. When the tumors reached an average size of $60-80 \mathrm{~mm}^{3}$, the nude mice received intratumoral injections of $1 \times 10^{9}$ plaqueforming units (pfu) of oncolytic adenovirus diluted in 50 $\mu \mathrm{L}$ of PBS or PBS alone. The adenoviruses used were defective control adenovirus (Ad-shNC) and TGF- $\beta 1$ or TGF- $\beta 2$ shRNA-expressing defective adenoviruses (Ad-sh TGF- $\beta 1$, Ad-shTGF- $\beta 2$ ). Intratumoral injection was repeated three times every other day. Regression of tumor growth was assessed by taking measurements of the length $(L)$ and width $(W)$ of the tumor. Tumor volume was calculated using the following formula: volume $=$ $0.52 \times L \times W^{2}$.

\section{Immunohistochemistry (IHC)}

For IHC, tumor tissues were extracted, fixed for $24 \mathrm{~h}$ in $10 \%$ formaldehyde, and embedded in paraffin. IHC staining was performed as follows. Tissue sections were deparaffinized twice with xylene for $10 \mathrm{~min}$ and were rehydrated using a graded alcohol series. After removing endogenous peroxidases using $0.1 \% \mathrm{H}_{2} \mathrm{O}_{2}$, sections were washed three times with PBS. Antigen retrieval was achieved by incubating the sections in $10 \mathrm{mM}$ citrate buffer (pH 6.0) (DAKO, Glostrup, Denmark) using a microwave oven. Then the sections were permeabilized with $0.5 \%$ PBX (0.5\% Triton X-100 in PBS) for $30 \mathrm{~min}$ and washed three times with PBS. After blocking for $1 \mathrm{~h}$ with $5 \% \mathrm{BSA}$, the primary antibody was added, and the sections were incubated overnight at $4{ }^{\circ} \mathrm{C}$. Primary Antibody Enhancer (Thermo Fisher Scientific, Waltham, MA, USA) and horseradish peroxidase Polymer (Thermo Scientific) were used for signal amplification. To develop the colored product, a mixture of DAB (3,3'-diaminobenzidine) Plus Chromogen and DAB Plus Substrate (Thermo Fisher Scientific) was added for $5 \mathrm{~min}$. After washing with PBS, $20 \%$ hematoxylin counterstain was added for $2-5$ min to stain the nuclei. Finally, the tissue sections were dehydrated in a graded alcohol series. After clearing twice in xylene, the tissue sections were coverslipped with mounting media (xylene:mount $=1: 1$ ) for microscopy.

\section{TUNEL assay}

To measure in situ apoptosis, a terminal deoxynucleotidyl transferase-mediated dUTP nick end labeling (TUNEL) assay was performed using tumor tissue sections prepared as described for IHC. The TUNEL assay was carried out according to the manufacturer's instructions (Promega, Madison, WI, USA).

\section{Statistical analysis}

The data are expressed as the mean \pm standard error (SE). Differences between groups were examined using unpaired two-tailed $t$ tests. Statistical comparison was made using the Graph Pad (Systat Software Inc.). $p$ Values $<0.05$ were considered statistically significant $(" p<0.05$; $* p<0.01)$.

\section{Results}

Downregulation of TGF- $\beta 1$ and TGF- $\beta 2$ after infection with adenoviruses expressing shRNAs of TGF- $\beta$

Almost all human tumors overexpress TGF- $\beta$, primarily TGF- $\beta 1$ and TGF- $\beta 2$, which contribute to the induction of tumor cell invasion and metastasis ${ }^{47}$. To decrease the expression of TGF- $\beta 1$ and TGF- $\beta 2$, we infected human 
melanoma (A375) or pancreatic cancer (HPAC) cells with recombinant adenoviruses containing shRNA for TGF- $\beta 1$ or TGF- $\beta 2$ (shTGF- $\beta 1$ or shTGF- $\beta 2$, respectively) at various MOIs $(10,50$, and 100$)$. The shRNA sequences used in the experiment after screening several candidate target sequences originated from Oh et al. ${ }^{46}$ (Suppl. Figure $1 \mathrm{~A}, \mathrm{~B})$. The mRNA and protein levels of TGF- $\beta 1$ and TGF- $\beta 2$ were measured by real-time PCR and ELISA, respectively. The results show that TGF- $\beta 1 \mathrm{mRNA}$ levels were suppressed by $80 \%$ at an MOI of 100 , at which TGF$\beta 2$ mRNA levels were suppressed by $75 \%$ (Fig. 1a, b). Similarly, the protein levels of TGF- $\beta 1$ and TGF- $\beta 2$ were also reduced (Fig. 1a, c).

\section{shTGF- $\beta 1$ and shTGF- $\beta 2$ induce the phosphorylation of SAPKs}

Because high expression of TGF- $\beta$ is correlated with malignancy in many cancers ${ }^{3}$, we investigated the effect of TGF- $\beta$ downregulation in cancer cell lines. We first examined whether shTGF- $\beta 1$ or shTGF- $\beta 2$ could inhibit cancer cell survival using a clonogenic assay, which can measure long-term cancer cell survival. The results of the clonogenic assay revealed that the survival of various cancer cells was reduced after infection with adenoviruses carrying shTGF- $\beta 1$ or shTGF- $\beta 2$ (Fig. $1 b$ ). To examine the impact of TGF- $\beta$ downregulation on the overall gene fluctuation, a global transcriptomic response was assessed by microarray. Figure 1c shows clearly different patterns of $z$ scores after clustering analysis between control cells (A375 and HPAC cells) and TGF- $\beta$-downregulated control cells, suggesting a possibility of substantial gene fluctuation toward cell death after TGF- $\beta$ downregulation (Supple. Figure 2). To further demonstrate that cell death by TGF- $\beta$ downregulation is also caused by SAPK pathways, we examined various key signaling molecules of SAPK pathways. We observed that the levels of phosphorylated-p38 (phospho-p38), phosphorylatedHSP27 (phospho-HSP27), phosphorylated-JNK (phospho-JNK), and phosphorylated-ERK (phospho-ERK) were increased by shTGF- $\beta 1$ and shTGF- $\beta 2$ (Fig. 1d). However, after TGF- $\beta$ downregulation in normal pancreatic cells, the phosphorylation levels of various key signaling pathway molecules, including HSP27, JNK, and ERK, did not change (Fig. 1e). To determine whether shTGF- $\beta 1$ or shTGF- $\beta 2$ produced off-target effects, we analyzed A375 cells infected with adenoviruses carrying the shRNAs and supplemented the cells with recombinant TGF- $\beta$ protein. Western blot analyses showed that the addition of recombinant TGF- $\beta 1$ protein restored the levels of phospho-src, phospho-p65, phospho-stat3, phosphoHSP27, and phospho-p38 (Suppl. Figure 3A). Additionally, morphological recovery was also observed (Suppl. Figure 3B). Similar patterns were also observed with recombinant TGF- $\beta 2$ protein (Suppl. Figure $3 C$, D), suggesting that there were no off-target effects of shTGF$\beta 1$ or shTGF- $\beta 2$. Then we investigated whether TGF- $\beta$ itself could also activate p38 in the cancer cells in which TGF- $\beta$ downregulation activated p38. Supplementary figure 4 shows the weak activation of p38 in cancer cells and specific survival molecules, for example, p65 in A375 cells or Akt and stat3 in HPAC cells, after TGF- $\beta 1$ treatment with no complete sign of cell death.

\section{shTGF- $\beta 1$ and shTGF- $\beta 2$ induce ROS generation in cancer cells}

ROS are known to be related to JNK and p38 pathway activation $^{48-50}$. Thus we assessed the generation of ROS in A375 and HPAC cells infected with adenoviruses carrying shRNAs for TGF- $\beta 1$ and TGF- $\beta 2$. We found that knockdown of TGF- $\beta 1$ greatly stimulated the generation of ROS in A375 cells $48 \mathrm{~h}$ after adenovirus infection. In contrast, few ROS were generated in A375 cells after knockdown of TGF- $\beta 2$ or in HPAC cells after knockdown of TGF- $\beta 1$ or TGF- $\beta 2$, and ROS were barely detectable in normal pancreatic cells after TGF- $\beta$ downregulation (Fig. 1f), which was primarily derived from low infection efficiency in normal pancreatic cells (data not shown). $\mathrm{N}$ acetylcysteine (NAC) is an aminothiol and a synthetic precursor of intracellular cysteine and glutathione and is thus considered a strong antioxidant ${ }^{51}$. Because shTGF$\beta 1$ induced ROS in A375 cancer cells, we next evaluated the effect of NAC on cell growth and apoptosis. We found that, as predicted, NAC treatment reduced ROS levels in A375 cells. (Fig. 1g). Furthermore, cell death was inhibited (Fig. 1g, h), suggesting that ROS production was responsible for the cancer cell death induced by TGF- $\beta 1$ downregulation; however, cell death still occurred without much ROS generation in HPAC cells (Fig. 1g, h).

\section{NOX4 is responsible for ROS generation induced by the downregulation of TGF- $\beta$}

Next, we examined various ROS-generating enzymes, including NOX1, NOX4, and 5-lipoxygenase. Nicotinamide adenine dinucleotide phosphate oxidase is one of the main sources implicated in the production of cellular $\operatorname{ROS}^{52,53}$. Among the ROS-generating enzymes, NOX4 was strongly expressed after TGF- $\beta 1$ downregulation but not after TGF- $\beta 2$ downregulation (Fig. 2a), and its expression induced by TGF- $\beta 1$ downregulation was almost completely repressed by constitutive Akt activation in A375 cells (Fig. 2b). However, NOX4 was not detected in HPAC cells. Figure 2c shows that NOX4 mRNA levels in HPAC cells, compared with those in A375 cells, were barely detectable. Intriguingly, NOX4 expression was also repressed by ROS inhibition or p38 inhibition, which are downstream molecules of NOX4 (Fig. $2 \mathrm{~d}-\mathrm{f}$ ), suggesting that a positive feedback loop was formed to sustain cancer cell death in A375 cells. 


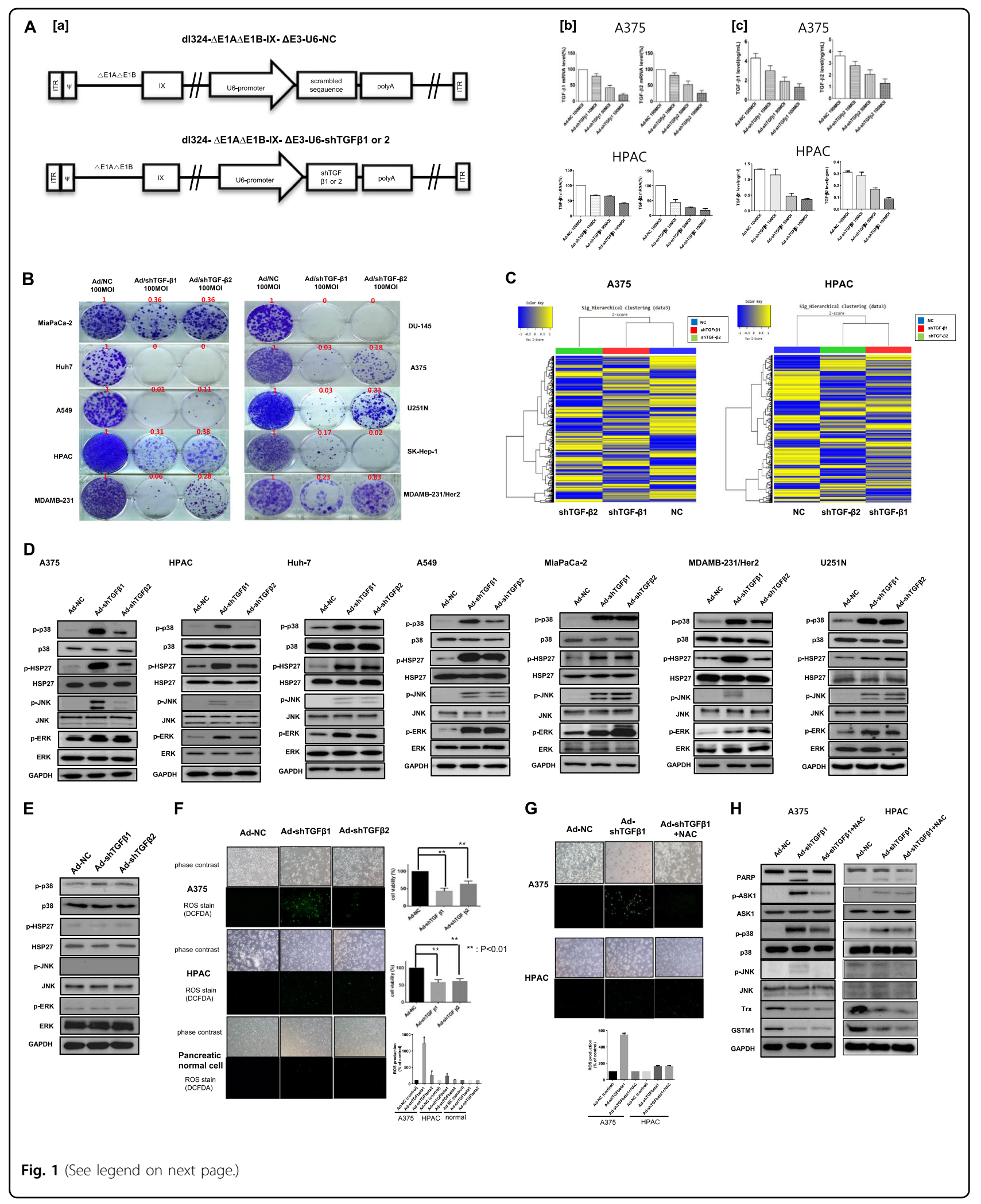


(see figure on previous page)

Fig. 1 TGF- $\beta$ downregulation and ROS generation by TGF- $\beta$ shRNAs. A Downregulation of TGF- $\beta 1$ and TGF- $\beta 2$ after infection with adenoviruses expressing TGF- $\beta$ shRNAs. a Schematic structure of adenoviral vectors expressing TGF- $\beta$ shRNA. dl324- $\triangle E 1 A-\triangle E 1 B-\triangle E 3-I X-U 6-N C$ (Ad-NC) is a replication-incompetent adenovirus used as the negative control. It contains the scrambled DNA sequence for shRNA, which is under the control of the U6 promoter. dI324- $\triangle E 1 A-\triangle E 1 B \Delta E 3-I X-U 6$-shTGF- $\beta 1$ or - $\beta 2$ (Ad-shTGF- $\beta 1$ or - $\beta 2$ ) is a replication-incompetent adenovirus expressing human TGF$\beta 1$ or $-\beta 2$ shRNA. NC negative control. b Downregulation of human transforming growth factor $\beta 1$ (TGF- $\beta 1$ ) or $\beta 2$ by adenovirus expressing shTGF- $\beta 1$ or $-\beta 2$. Human A375 and HPAC cells were infected with various MOls of adenovirus expressing shRNA targeting human TGF- $\beta 1$ (Ad-shTGF- $\beta 1$ ) or human TGF- $\beta 2$ (Ad-shTGF- $\beta 2$ ) or scrambled RNA (Ad-NC). TGF- $\beta 1$ or - $\beta 2$ mRNA was assayed by quantitative real-time polymerase chain reaction (qRT-PCR), and $\mathbf{c}$ protein levels were assayed by enzyme-linked immunosorbent assay (ELISA). MOI multiplicity of infection, NC negative control. Error bars represent the standard error from three independent experiments. B Various cancer cell lines were treated with adenovirus expressing shTGF- $\beta 1$ or $-\beta 2$ for $48 \mathrm{~h}$ and incubated for an additional 14 days for clonogenic assays. The numbers indicate the relative ratio of clone numbers to those of Ad-NC. C Global transcriptome analysis of TGF- $\beta$ downregulation. Expression values of differentially expressed genes are shown in heat map format. Gene expression levels are visualized as row standardized $z$ scores ranging from green $(-1)$ to red $(+1)$ across all samples. The rows are organized by hierarchical clustering analysis with complete linkage and Euclidean distance as a measure of similarity from samples of A375 cells (NC, shTGF- $\beta 1$, shTGF- $\beta 2$ ) (Left) and HPAC cells (NC, shTGF- $\beta 1$, shTGF- $\beta 2$ ) (Right). NC, A375, and HPAC cells infected with adenovirus expressing nonsense shRNA as a negative control at $100 \mathrm{MOI}$; shTGF- $\beta 1$ or $-\beta 2$; $A 375$ and HPAC cells infected with adenoviruexpressing TGF- $\beta 1$ or $-\beta 2$ shRNA at $100 \mathrm{MOI}$. D Effect of adenovirus expressing shTGF- $\beta 1$ or shTGF- $\beta 2$ in various cancer cell lines. Each cell line was treated with adenovirus expressing shTGF- $\beta 1$ or shTGF- $\beta 2$ at $100 \mathrm{MOI}$. After $48 \mathrm{~h}$, the expression levels of p-p38, p38, p-HSP27, HSP27, p-ERK, ERK, p-JNK, JNK, and GAPDH were detected via western blot analysis. E Pancreatic normal cell lines were treated with adenovirus expressing shTGF- $\beta 1$ or $-\beta 2$ at $100 \mathrm{MOI}$. After $48 \mathrm{~h}$, the expression levels of $p$-p38, p38, p-HSP27, HSP27, p-ERK, ERK, p-JNK, JNK, and GAPDH were detected via western blot analysis. F ROS generation was induced by shTGF- $\beta 1$ - and shTGF- $\beta 2$-expressing adenoviruses. A375 cells, HPAC cancer cells, and pancreatic normal cells were infected with adenovirus expressing shTGF- $\beta 1$ or $-\beta 2$ at $100 \mathrm{MOI}$, respectively, after $48 \mathrm{~h}$ of incubation with DCF-DA $(20 \mu \mathrm{M}, 1 \mathrm{~h})$ for the detection of ROS using a fluorescent reader and microscopy. Cell viability was tested via an MTS viability assay after $48 \mathrm{~h}$ of infection. Error bars represent the standard error from three independent experiments. $p$ Values $<0.01$ indicate a very significantly different viability of Ad-shTGF- $\beta 1$ or $-\beta 2$ compared to the control (Ad-NC). G Effects of NAC treatment with adenovirus expressing TGF- $\beta 1$ or - $\beta 2$ shRNA in melanoma and pancreatic cancer cells. A375 (top) or HPAC (bottom) cells were infected with adenovirus expressing shTGF- $\beta 1$ or $-\beta 2$ at $100 \mathrm{MOI}$, respectively. After $6 \mathrm{~h}$, infected cells were treated with NAC (10 mM) for $42 \mathrm{~h}$ and then incubated with DCF-DA $(20 \mu \mathrm{M}, 1 \mathrm{~h})$ for the detection of ROS using a fluorescent reader and microscopy. $\mathbf{H}$ A375 and HPAC cells were infected with adenovirus expressing shTGF- $\beta 1$ or $-\beta 2$. After $6 \mathrm{~h}$, infected cells were treated with NAC (10 mM) for $42 \mathrm{~h}$, and then the expression levels of PARP, p-ASK1, ASK1, pp38, p38, p-JNK, JNK, Trx, and GAPDH were detected by western blot analysis

However, the Smad signaling pathway was not involved in NOX4 generation (Fig. 2f, g). To demonstrate NOX4 function as an indispensable part of TGF- $\beta 1$ downregulation-induced cancer cell death in A375 cells, both NOX4 siRNA and GKT137831 (ApexBio, Houston, TX, USA) as a NOX4 inhibitor were used to determine whether its inhibition could reverse TGF- $\beta 1$ downregulationinduced ROS generation/ER stress and subsequent cancer cell death. Figure $2 \mathrm{~h}$, i demonstrated that NOX4 was an essential mediator of TGF- $\beta 1$ downregulation-induced cancer cell death in A375 cells. However, owing to the nature of dual NOX1/NOX4 inhibition of GKT137831, NOX1 siRNA was also used to check the possibility of NOX1 involvement in TGF- $\beta 1$ downregulation-induced ROS generation/ER stress and subsequent cancer cell death. As a result, NOX1 was not found to be involved in this pathway (Fig. 2j).

\section{ASK1 functions as a key mediator of TGF- $\beta 1$ downregulation-induced cell death}

As ASK1 and SAPKs were activated during TGF- $\beta 1$ downregulation-induced apoptosis in A375 and HPAC cells, we investigated whether the ASK1 signaling cascade was the main regulator of this pathway. As shown in Fig. 3, downregulation of ASK1 using ASK1 siRNA restored the viability (Fig. 3a) and morphology (Fig. 3b) of cells following TGF- $\beta$ downregulation. Furthermore, ASK1 siRNA also reversed SAPK activation, including ASK1 activation. Interestingly, survival signals including Akt, src, or stat3 activation and Trx/GSTM1 showed nearly no recovery (Fig. 3c). To confirm that ASK1 activation drives cell death following TGF- $\beta$ downregulation, we constructed and utilized an inactive ASK1 mutant, ASK1 (K709M). Similar results were also obtained using this mutant and ASK1 inhibition using siRNA (Fig. 3d-f).

\section{Non-canonical signaling through Akt inactivation by TGF- $\beta$ downregulation triggers ROS-ASK1 axis activation}

Then we investigated the source of ROS-ASK1 axis activation and found that the Smad signaling pathway was not involved in TGF- $\beta$ downregulation-induced ROS generation (Fig. 3g) or ER stress (Fig. 3h). Therefore, PI3K-Akt, as a well-known non-canonical TGF- $\beta$ signaling pathway, was investigated to determine whether it was the main source of ROS generation using a constitutively active form of Akt, N-terminally myristoylation signalattached Akt (myr-Akt). As expected, TGF- $\beta$ downregulation-induced ROS generation was greatly decreased by Akt activation (Fig. 3i). The decrease in ROS caused by Akt activation also decreased both ER stress and 


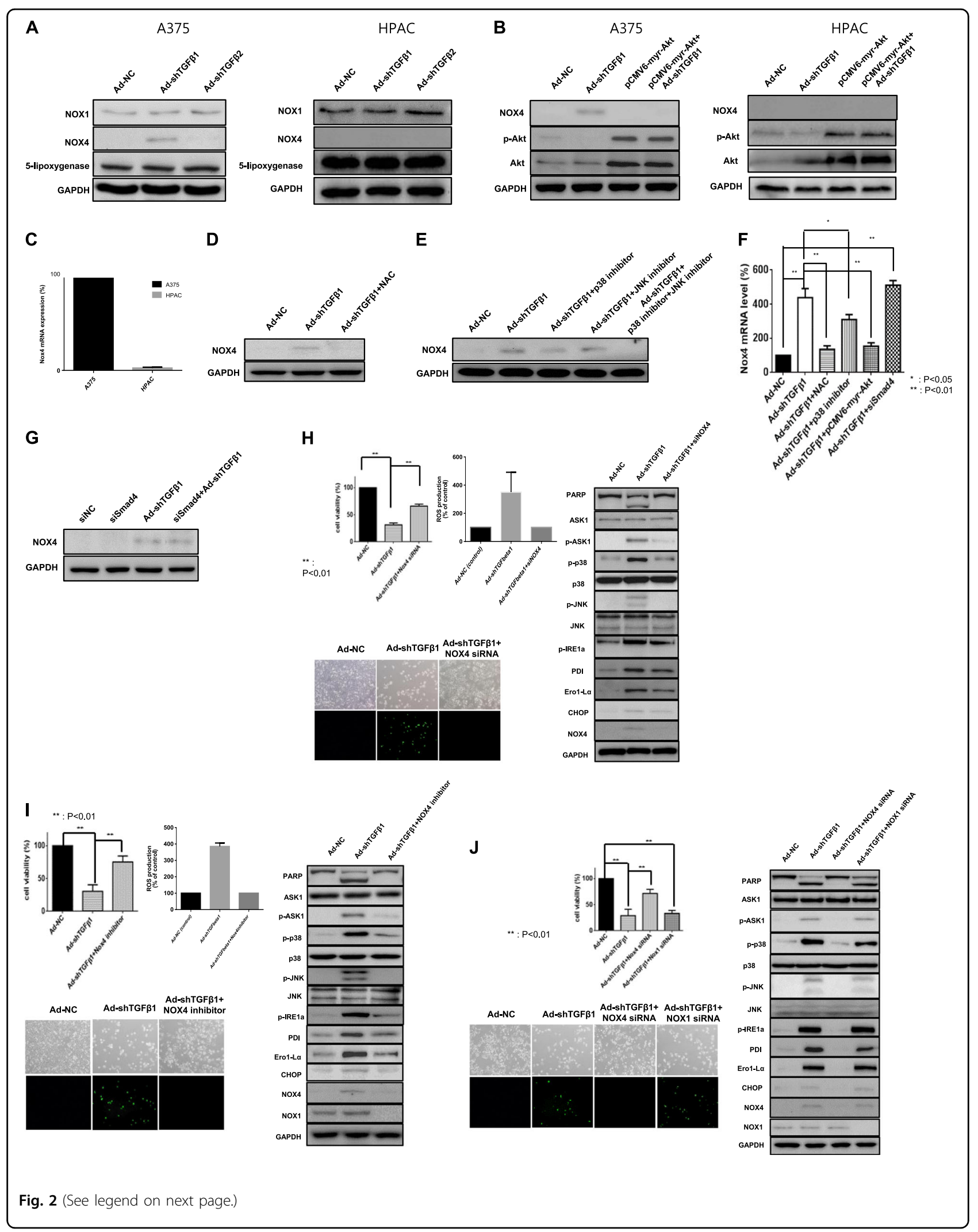


(see figure on previous page)

Fig. 2 NOX4 is responsible for TGF- $\beta$ downregulation-induced ROS generation. a A375 and HPAC cells were infected with adenovirus expressing shTGF- $\beta 1$ or $-\beta 2$ at $100 \mathrm{MOI}$, respectively. After $48 \mathrm{~h}$, the expression levels of NOX1, NOX4, 5-lipoxygenase, and GAPDH were detected by western blot analysis. b A375 and HPAC cells were infected with adenovirus expressing shTGF- $\beta 1$ or transfected with pCMV6-myr-Akt or infected with adenovirus expressing shTGF- $\beta 1$ and subsequently transfected with pCMV6-myr-Akt. After 48 h, NOX4, phospho-Akt, Akt, and GAPDH were detected by western blot analysis. $\mathbf{c}$ Expression levels of NOX4 mRNA in A375 and HPAC cells were assayed by quantitative real-time polymerase chain reaction (qRT-PCR). d A375 cells were infected with adenovirus expressing shTGF- $\beta 1$. After $6 \mathrm{~h}$, infected cells were treated with NAC (10 mM) for $42 \mathrm{~h}$, and then the expression of NOX4 and GAPDH was detected by western blot analysis. e A375 cells were infected with adenovirus expressing shTGF- $\beta 1$ at 100 $\mathrm{MOI}$, and after $6 \mathrm{~h}$, infected cells were treated with p38 inhibitor (SB203580, $10 \mu \mathrm{M}$ ) or JNK inhibitor (SP600125, $10 \mu \mathrm{M})$ or both for $42 \mathrm{~h}$. Then the expression of NOX4 and GAPDH was detected by western blot analysis. f A375 cells were infected with adenovirus expressing shTGF- $\beta 1$ at 100 MOI or adenovirus expressing shTGF- $\beta 1$ followed by NAC (10 mM) or adenovirus expressing shTGF- $\beta 1$ followed by p38 inhibitor (SB203580, $10 \mu M)$ or adenovirus expressing shTGF- $\beta 1$ followed by transfection with pCMV6-myr-Akt or adenovirus expressing shTGF- $\beta 1$ followed by transfection with siRNA of Smad4 based on the siRNA transfection protocol (Santa Cruz, CA, USA). After 48 h, the expression levels of NOX4 mRNA were assayed by quantitative real-time polymerase chain reaction (qRT-PCR). Error bars represent the standard error from three independent experiments. Asterisks indicate a significant difference compared to each given control ( $\left.{ }^{*} p<0.05 ;{ }^{* *} p<0.01\right)$. g A375 cells were infected with adenovirus expressing shTGF$\beta 1$ at $100 \mathrm{MOl}$ or adenovirus expressing shTGF- $\beta 1$ followed by transfection with siRNA of Smad4. After $48 \mathrm{~h}$, NOX4 and GAPDH were detected by western blot analysis. $\mathbf{h}$ A375 cells were infected with adenovirus expressing shTGF- $\beta 1$ at $100 \mathrm{MOl}$ or adenovirus expressing shTGF- $\beta 1$ followed by transfection with siRNA of NOX4 based on the siRNA transfection protocol (Santa Cruz, CA, USA). After $48 \mathrm{~h}$, cell viability was tested via an MTS viability assay (upper left), or cells were incubated with DCF-DA $(20 \mu \mathrm{M}, 1 \mathrm{~h})$ for the detection of ROS using a fluorescent reader and microscopy (upper right, lower left) or the expression levels of various ER stress markers; in addition, PARP, p-ASK1, ASK1, p-p38, p38, p-JNK, and JNK were detected by western blot analysis (right). i A375 cells were infected with adenovirus expressing shTGF- $\beta 1$ at $100 \mathrm{MOl}$ or adenovirus expressing shTGF$\beta 1$ followed by treatment with NOX4 inhibitor (GKT137831, $140 \mathrm{nM}$ ). After $48 \mathrm{~h}$, cell viability was tested via an MTS viability assay (upper left), or cells were incubated with DCF-DA $(20 \mu \mathrm{M}, 1 \mathrm{~h})$ for the detection of ROS using a fluorescent reader and microscopy (upper right, lower left) or the expression levels of various ER stress markers; in addition, PARP, p-ASK1, ASK1, p-p38, p38, p-JNK, and JNK were detected by western blot analysis (right). j A375 cells were infected with adenovirus expressing shTGF- $\beta 1$ at $100 \mathrm{MOI}$ or adenovirus expressing shTGF- $\beta 1$ followed by transfection with siRNA of NOX4 or NOX1 based on the siRNA transfection protocol (Santa Cruz, CA, USA). After 48 h, cell viability was tested via an MTS viability assay (upper left), or cells were incubated with DCF-DA $(20 \mu \mathrm{M}, 1 \mathrm{~h})$ for the detection of ROS using a fluorescent reader and microscopy (upper right, lower left) or the expression levels of various ER stress markers; in addition, PARP, p-ASK1, ASK1, p-p38, p38, p-JNK, and JNK were detected by western blot analysis (right)

ASK1-p38/JNK cascade-induced apoptosis (Fig. 3j-1). These results support the strong correlation between the lack of effect on Akt inactivation and the loss of NOX4 expression/trivial ROS production following TGF- $\beta 1$ downregulation in HPAC cells

\section{TGF- $\beta$ downregulation decreases Trx and GSTM1 expression and the formation of complexes with ASK1}

Next, we investigated how HPAC cells die concomitant with ASK1 activation and trivial ROS production. We found that TGF- $\beta$ downregulation decreased both the mRNA and protein levels of Trx and GSTM1, both of which act as negative ASK1-interacting regulators by inhibiting ASK1 kinase activity and cytotoxicity in both A375 and HPAC cells (Fig. 4a, b). Moreover, the interactions between Trx and ASK1 and between GSTM1 and ASK1 were also reduced by TGF- $\beta$ downregulation, particularly by TGF- $\beta 1$ downregulation (Fig. 4c). In contrast, NAC treatment restored the interactions between Trx and ASK1 and between GSTM1 and ASK1, which is likely related to the repression of ROS production (Fig. 4d). These results strongly suggest that an increase in ASK1 activity follows both reduced Trx and GSTM1 expression and the dissociation of ASK1-Trx and ASK1-GSTM1 complexes. However, this increased ASK1 activity leads to HPAC cancer cell death only by reduced Trx and GSTM1 expression.
Regulation of Trx and GSTM1 promoter activity and AP-1, Sp1, and Smad expression by TGF- $\beta$

Because TGF- $\beta$ downregulation suppressed Trx and GSTM1 expression, we examined their promoter sequences to identify the possible mechanism underlying this finding. The Trx promoter contains several consensus AP-1 (21) and Sp1 (2) binding sites, whereas the GSTM1 promoter contains AP-1-binding sites (30) but not the Sp1-binding site, as revealed by the Champion ChiP transcription factor search program supplied by Qiagen (Germantown, MD, USA). We found that TGF- $\beta$ downregulation decreased Trx and GSTM1 promoter binding by $\mathrm{Sp} 1$ and Ap1 proteins (Fig. 5a), most likely due to decreased AP-1 and Sp1 protein levels (Fig. 5b). As canonical TGF- $\beta$ signaling primarily regulates gene transcription via Smads ${ }^{54}$, we investigated the levels of activated Smad proteins following infection with adenoviruses expressing shRNAs for TGF- $\beta 1$ or TGF- $\beta 2$. Western blot analysis showed that the expression levels of phospho-Smad2 and phospho-Smad3 were decreased (Fig. 5c). In addition, IP results also demonstrated reduced interactions of AP-1 and Sp1 with Smad proteins (Fig. 5d), suggesting that the reduction in the Smad complex, including Smad4, makes it difficult to mobilize to the nucleus, where these proteins act as transcription factors. In support of the inability of Smad4 to translocate to the nucleus during TGF- $\beta$ downregulation, Smad4 


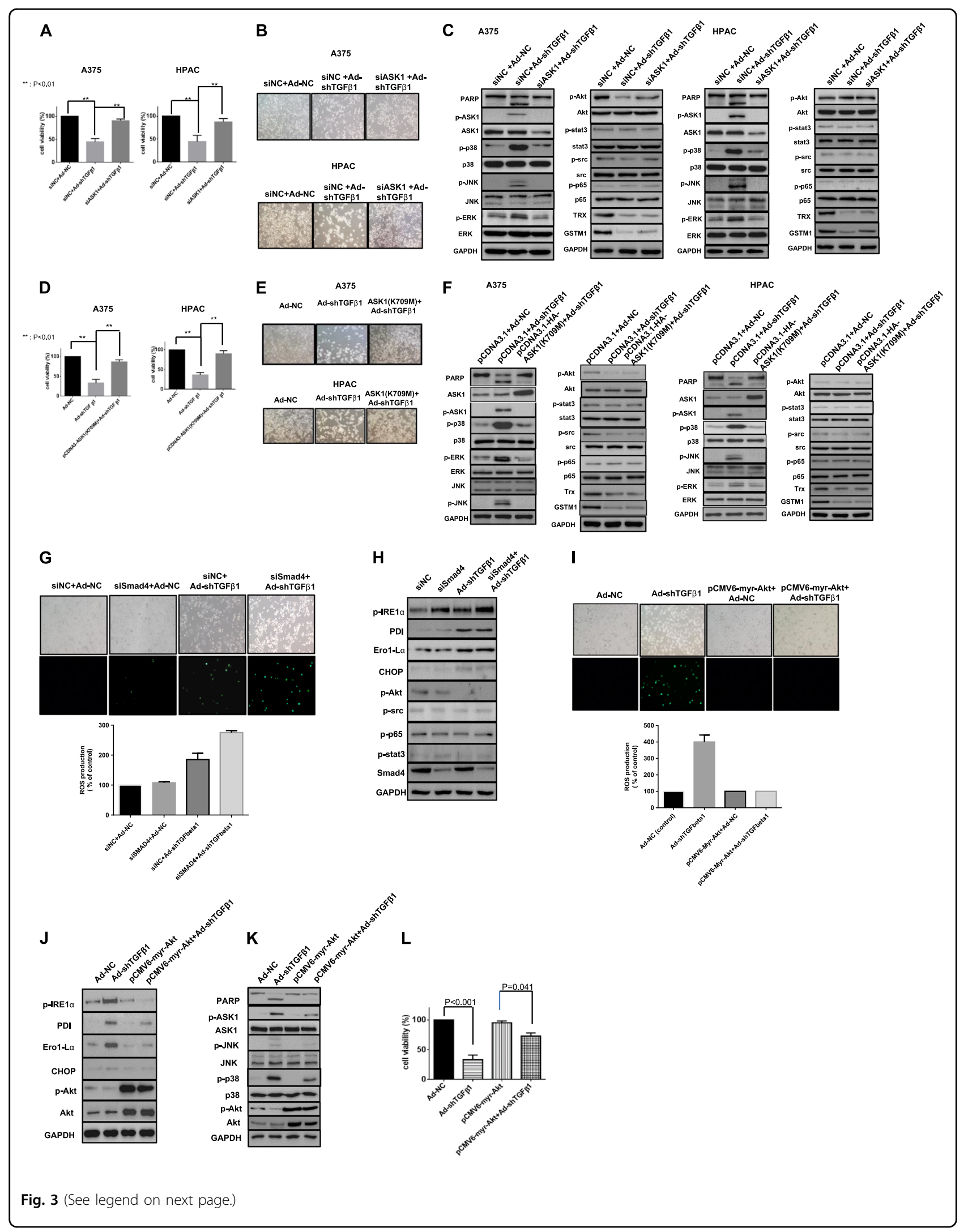


(see figure on previous page)

Fig. 3 ASK1 functions as a key mediator of TGF- $\beta$ downregulation-induced cell death triggered by non-canonical signaling Akt inactivation a ASK1 mediates TGF- $\beta$-induced cell death via p38/JNK activation. A375 and HPAC cells were infected with adenovirus expressing shTGF- $\beta 1$ or $-\beta 2(100 \mathrm{MOI})$ and subsequently transfected with siASK1. siASK1 transfection was based on the siRNA transfection protocol (Santa Cruz, CA, USA). After $48 \mathrm{~h}$, cell viability was tested by an MTS viability assay. Error bars represent the standard error from three independent experiments. Asterisks indicate a significant difference compared to each given control $\left({ }^{*} p<0.05 ;{ }^{*} p<0.01\right)$. b A375 and HPAC cells were infected with adenovirus expressing shTGF- $\beta 1$ or $-\beta 2$ and subsequently transfected with siASK1. After $48 \mathrm{~h}$, morphological changes were observed using microscopy. c A375 and HPAC cells were infected with adenovirus expressing shTGF- $\beta 1$ or $-\beta 2$ and subsequently transfected with siASK1. After 48 h, the expression levels of p-p38, p-Akt, p-HSP27, HSP27, p-ERK, p-src, p-p65, p-JNK, p-stat3, and GAPDH were detected by western blot analysis. $\mathbf{d}$ A375 and HPAC cells were infected with adenovirus expressing shTGF- $\beta 1$ or $-\beta 2$ and subsequently transfected with ASK1 kinase mutant ASK1 (K709M). After $48 \mathrm{~h}$, cell viability was tested with an MTS viability assay. Error bars represent the standard error from three independent experiments. Asterisks indicate a significant difference compared to each given control $\left({ }^{*} p<0.05 ;{ }^{* *} p<0.01\right)$. e A375 and HPAC cells were infected with adenovirus expressing shTGF- $\beta 1$ or $-\beta 2$ and subsequently transfected with ASK1 kinase mutant ASK1 (K709M). After 48 h, morphological changes were observed using microscopy. $\mathbf{f}$ A375 and HPAC cells were infected with adenovirus expressing shTGF- $\beta 1$ or $-\beta 2$ and subsequently transfected with ASK1 kinase mutant ASK1 (K709M). After 48 h, the expression levels of p-p38, p-Akt, p-HSP27, HSP27, p-ERK, p-src, p-p65, p-JNK, p-stat3, and GAPDH were detected by western blot analysis. $\mathbf{g}$ A375 cells were infected with adenovirus expressing shTGF- $\beta 1$ and subsequently transfected with siSmad4. After $48 \mathrm{~h}$ of incubation with DCF-DA (20 $\mu \mathrm{M}, 1 \mathrm{~h})$, ROS were detected using a fluorescent reader and microscopy. $\mathbf{h}$ After $48 \mathrm{~h}$, the expression of various ER stress markers in addition to survival-related molecules was detected by western blot analysis; A375 cells were infected with adenovirus expressing shTGF$\beta 1$ and subsequently transfected with pCMV6-myr-Akt. i After $48 \mathrm{~h}$ of incubation with DCF-DA $(20 \mu \mathrm{M}, 1 \mathrm{~h})$, ROS were detected using a fluorescent reader and microscopy. $\mathbf{j}$ After $48 \mathrm{~h}$, the expression levels of various ER stress markers and phospho-Akt and Akt were detected by western blot analysis. $\mathbf{k}$ After $48 \mathrm{~h}$, the expression levels of PARP, p-ASK1, ASK1, p-p38, p38, p-JNK, JNK, and GAPDH were detected by western blot analysis. I After $48 \mathrm{~h}$, cell viability was tested via an MTS viability assay. Error bars represent the standard error from three independent experiments. Decreased $p$ value to 0.041 from $<0.001$ after Akt activation followed by TGF- $\beta 1$ downregulation means a significant decrease in cell death

localization in the nucleus was reduced, as observed by confocal immunofluorescence staining (Fig. 5e), and the reduced amount of Smad4 in the nucleus during TGF- $\beta$ downregulation was further confirmed by nucleus/cytosol fractionation (Fig. 5f). Smad4 downregulation confirmed that Smad4 is a key mediator of TGF- $\beta$ downregulationinduced Trx and GSTM1 suppression (Fig. 5g). However, intriguingly, NAC treatment did not recover the original state of phosphorylated Smad2, Smad3, or GSTM1/Trx prior to TGF- $\beta$ downregulation (Fig. $5 \mathrm{~h}$, i). These data suggest that the reduced expression of Trx and GSTM1 results from decreased levels of their transcriptional binding proteins, such as AP-1 and Sp1 and their subsequent reduced interactions with Smad proteins rather than from ROS generation.

\section{phospho-JNK/phospho-p38 functions as a bridge from ROS to the ASK1 axis in a positive feedback activation loop}

To investigate the possibility of ROS-mediated ER stress in TGF- $\beta$ downregulation, various ER stress-related molecules were examined. Higher expression levels of ER stress markers (CHOP, PDI, and Ero1-L $\alpha$ ) and increased phosphorylation of ER stress regulators (IRE1 $\alpha$ and phospho-PERK) were observed (Fig. 6a, left). The increase in ER markers was reduced by repression of ROS by NAC (Fig. 6a, right), and p38/JNK inhibition significantly recovered cell viability (Fig. $6 \mathrm{~b}$ ) with a concurrent decrease in ER stress-related molecules and ROS production (Fig. 6c, d). Moreover, similar events also occurred in cells after p38/JNK inhibition: a decrease in ASK1-Trx/GSTM1 dissociation (Fig. 6e) along with a decrease in PARP cleavage (Fig. 6f). Taken together, these results suggest that $\mathrm{p}-\mathrm{p} 38 / \mathrm{p}-\mathrm{JNK}$ and ROS cooperatively enhanced TGF- $\beta$ downregulation-induced cell death through persistent ER stress in A375 cells with NOX4 expression.

\section{Adenovirus expressing TGF- $\beta$ shRNA increases tumor regression in a mouse model}

To examine the in vivo potential of TGF- $\beta$ shRNAexpressing adenoviruses, we treated nude mice with A375 or HPAC cell grafts. After confirming TGF- $\beta$ downregulation following treatment with a replicationincompetent adenovirus expressing TGF- $\beta$ shRNA, replication-incompetent adenoviruses (expressing TGF$\beta 1$ or scrambled shRNA as an NC) were tested in nude mice for suppression of tumor growth compared to PBS. Tumor suppression in both cells increased in the order of Ad-shTGF- $\beta 1>$ Ad-NC $>$ PBS (Fig. 7a, upper). Likewise, the survival rate increased in the order of Ad-shTGF- $\beta 1>$ Ad-NC > PBS (Fig. 7a, bottom). The expression levels of adenovirus estimated by Hexon staining and TGF- $\beta 1$ in tumor tissue after infection were as expected, as determined by immunostaining (Fig. 7b). Apoptosis and necrotic events were also increased by an adenovirus containing TGF- $\beta$ shRNA (Fig. 7c).

In summary, downregulation of TGF- $\beta$ induces cancer cell death via the ASK1-SAPK axis signaling cascade. 


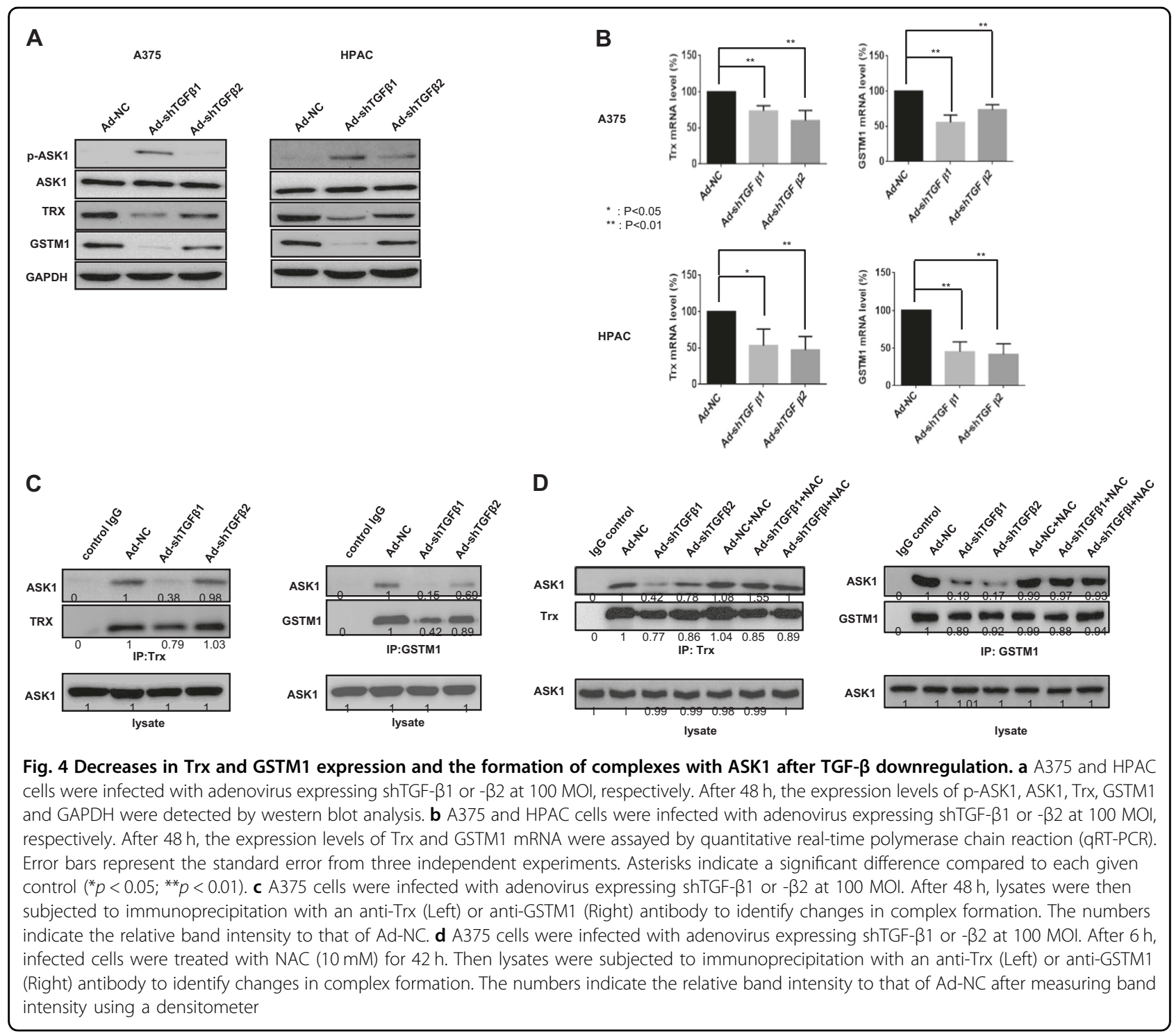

Figure $7 d$ provides a schematic diagram summarizing the results.

\section{Discussion}

The expression of TGF- $\beta$ isoforms is increased in many types of cancers. For example, a high level of TGF- $\beta 1$ has been detected in gastric cancer ${ }^{55}$, and levels of TGF- $\beta 1$ and TGF- $\beta 2$ are markedly increased in hepatocellular carcinoma and pancreatic cancer cells ${ }^{56,57}$. In addition, high TGF- $\beta$ levels are associated with resistance to anticancer treatments ${ }^{58}$. We found that shRNAs targeting TGF- $\beta 1$ or TGF- $\beta 2$ strongly inhibited the growth and survival of tumor cells.

We also found that ASK1 activation was induced by TGF- $\beta$ downregulation via two separate pathways. One pathway involved decreased gene expression of ASK1inhibitory binding proteins, and the other functioned through ROS generation and the dissociation of ASK1 protein complexes. Up to the present, Grx and Prx, in addition to Trx and GSTM1, are also known as redox sensors $^{59-62}$. In fact, endogenous cellular Grx levels in various cancer cells, including A375 and HPAC, were rarely detected (data not shown), whereas cellular Prx was detected in higher amounts in A375 cells. However, the cellular Prx level was not decreased, even after TGF- $\beta 1$ downregulation, and its interaction with ASK1 was rarely detected (Suppl. Figure 5). Therefore, we focused on the explanation of the ASK1-p38/JNK axis after TGF- $\beta$ downregulation with Trx and GSTM1. Furthermore, we found that TGF- $\beta$ downregulation repressed the transcription of Trx and GSTM1 via Smad signaling. In fact, in normal cells, Smad-mediated gene responses are not oncogenic, but in cancer cells, they become mediators of malignancy ${ }^{11}$. However, considering that some cancer 


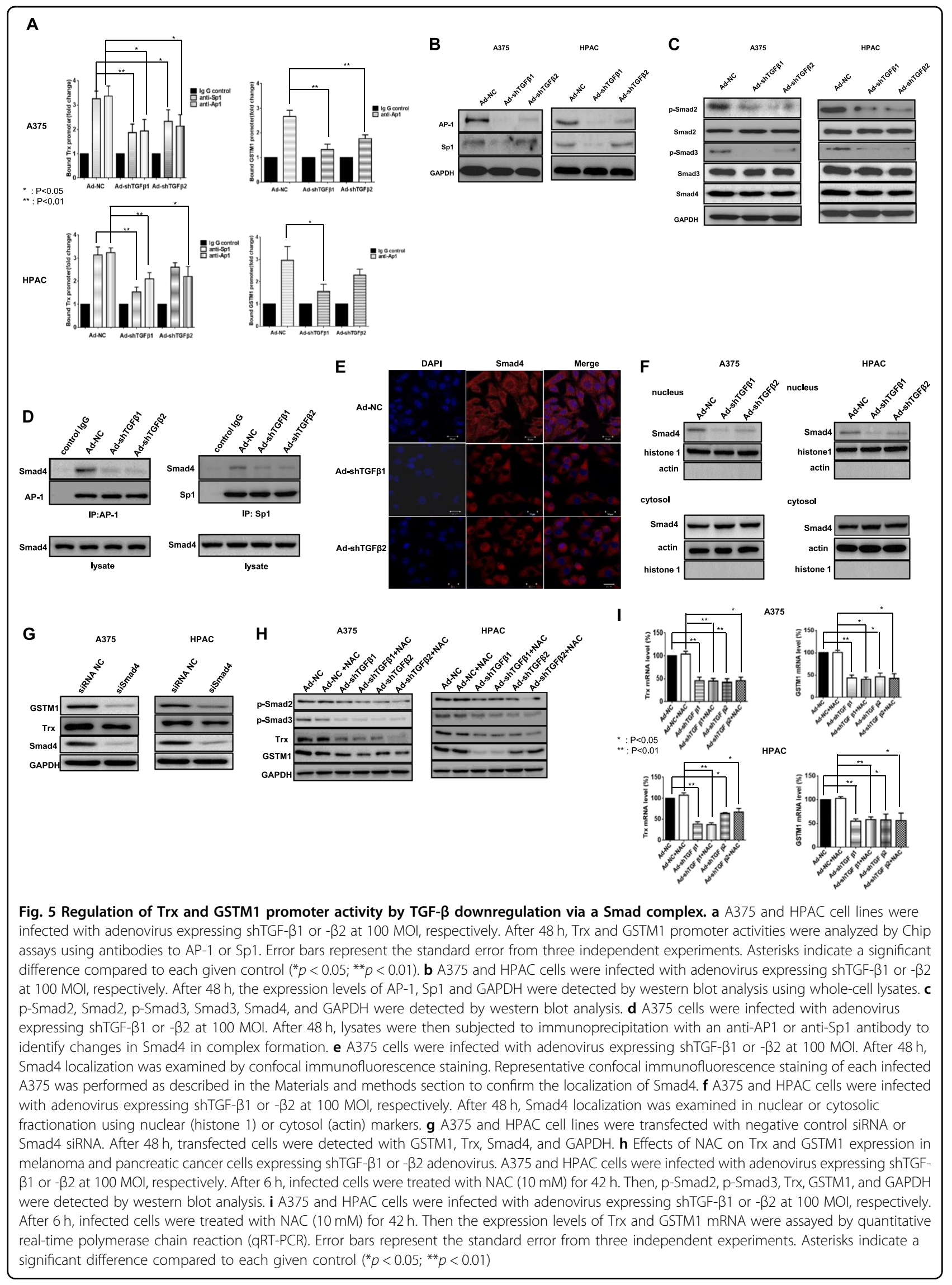

Official journal of the Korean Society for Biochemistry and Molecular Biology 


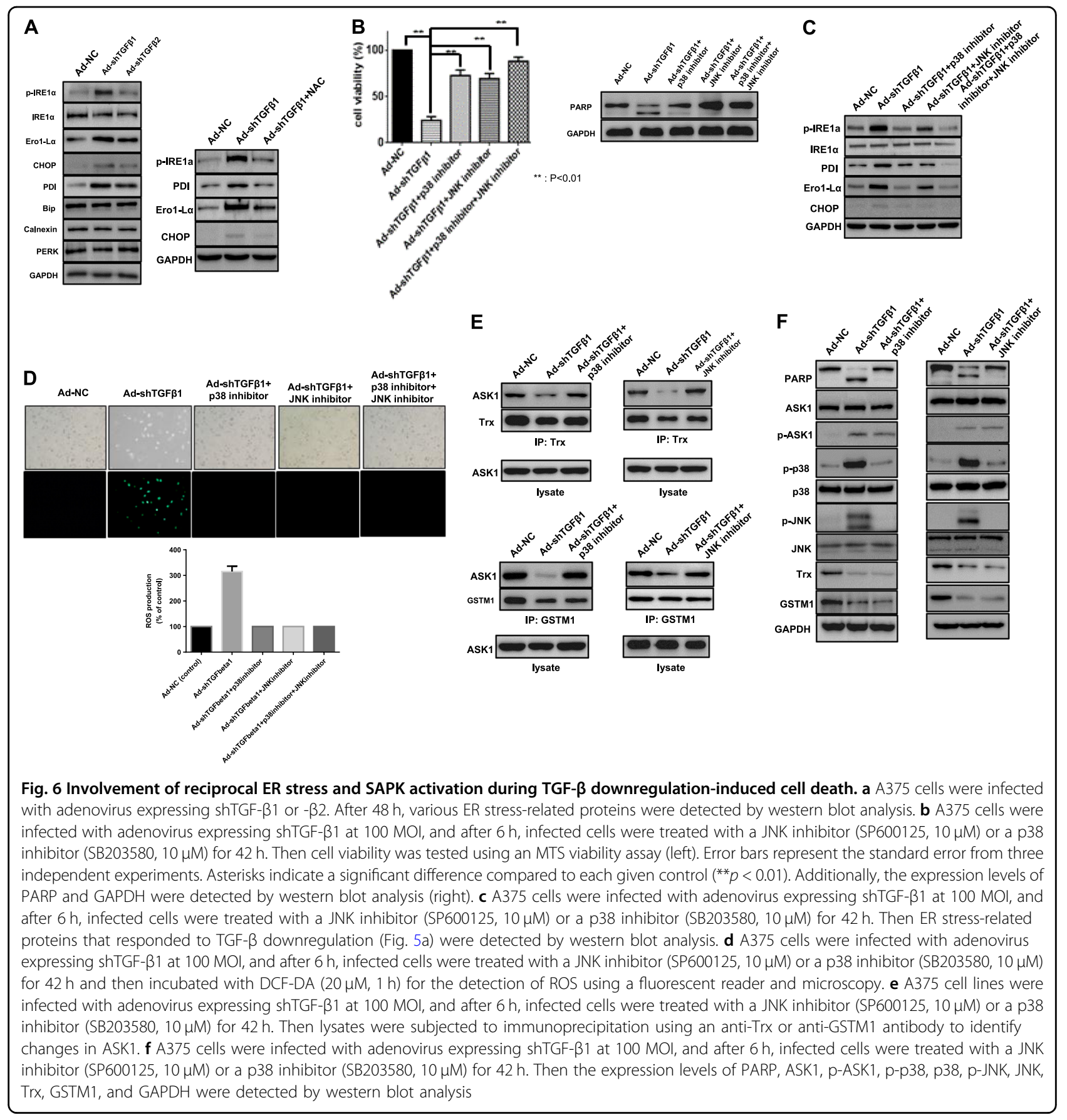

cells retain functional Smad signaling, the cellular context might determine whether this pathway promotes cancer, as demonstrated by TGF- $\beta$ signaling ${ }^{11}$.

In the context of physiological/pathophysiological settings, SAPKs are of vital importance to the life or death of a cell ${ }^{63}$. Their effects are determined by the precise nature of the extracellular stimuli and the repertoire of molecules available in the cell, which regulate the localization, timing, intensity, and duration of SAPK activation ${ }^{64}$. Owing to this complexity, the molecular understanding of how
JNK and p38 SAPK family members function as either tumor suppressors or oncoproteins in specific cell types remains unknown ${ }^{65}$. There are some reports that JNK and p38 have completely different functions depending on the duration of activation; transient JNK and p38 induction provides a survival signal, whereas persistent activation induces apoptosis ${ }^{29,66}$. In this study, we found that $\mathrm{p} 38$ activation (induced by TGF- $\beta$ downregulation) was particularly related to cancer cell death rather than cell survival due to both the sustained duration and strong 


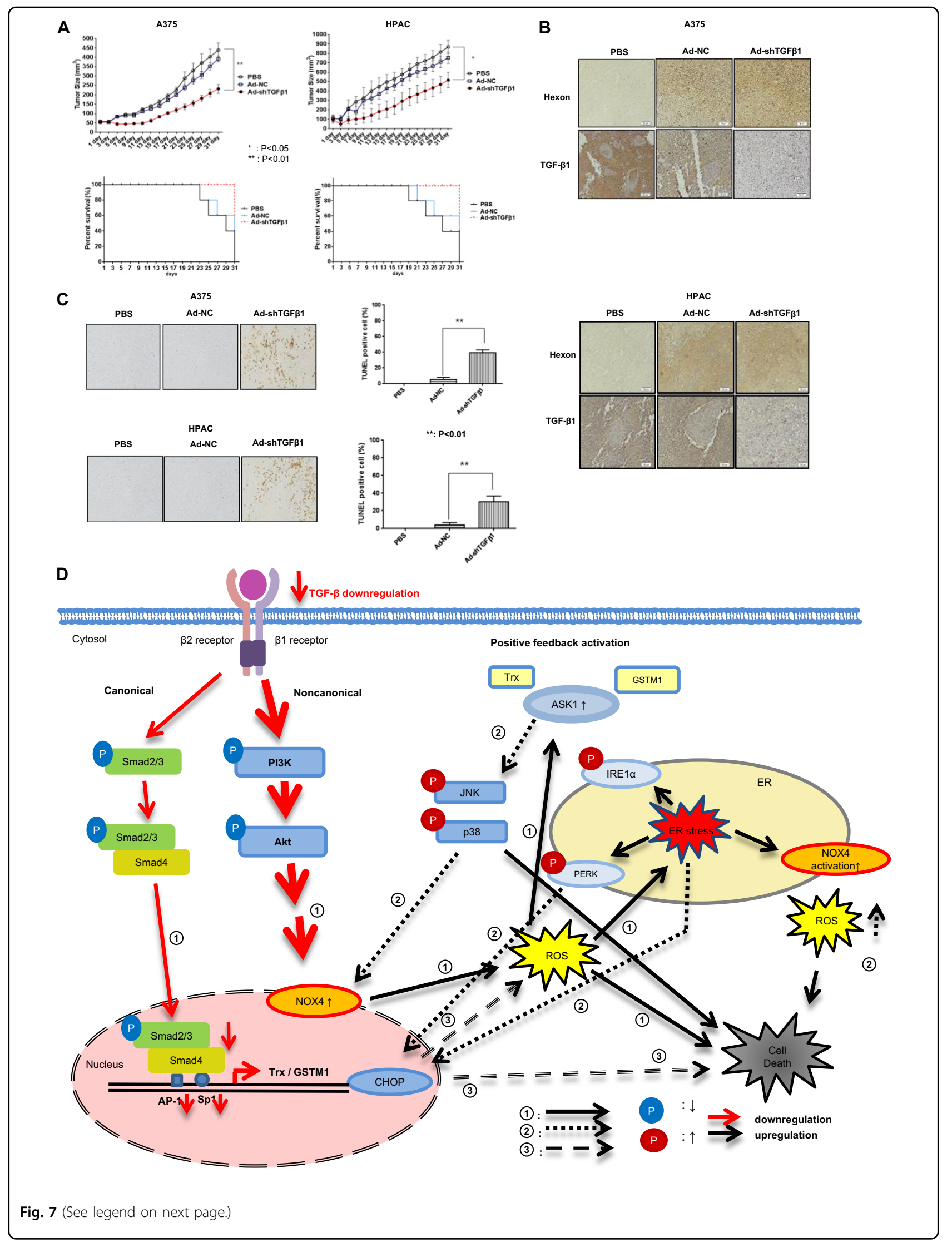


(see figure on previous page)

Fig. 7 Antitumor effect and schematic diagram of cancer cell death by TGF- $\beta$ downregulation. a BALB/C athymic nude mice were injected with $8 \times 10^{6} \mathrm{~A} 375$ or HPAC cells in $100 \mu \mathrm{L}$. When the tumors reached an average size of $60-80 \mathrm{~mm}^{3}$, the nude mice received intratumoral injections of $1 \times 10^{9}$ plaque-forming units (pfu) of various kinds of adenovirus (Ad-NC, Ad-shTGF- $\beta 1$, or Ad-shTGF- $\beta 2$ ) in $50 \mu L$ of PBS or PBS alone on days 1, 3, and 5. Tumor volume was monitored and recorded every 2 days until the end of the study. Values represent the mean \pm SE (five animals per group) (top). Asterisks indicate a significant difference compared to each given control $\left({ }^{*} p<0.05 ;{ }^{* *} p<0.01\right)$. Overall survival was determined throughout a 31-day time course (bottom). $\mathbf{b}$ Representative immunohistochemical analysis of recombinant adenovirus-infected tumor sections was performed as follows. Three animals per group of BALB/c athymic nude mice were injected with $8 \times 10^{6} \mathrm{~A} 375$ or HPAC cells/100 $\mu \mathrm{L}$ and treated with intratumoral injections of $1 \times 10^{9} \mathrm{pfu} / 50 \mu \mathrm{L}$ of various types of adenovirus (Ad-NC, Ad-shTGF- $\beta 1$, or Ad-shTGF- $\beta 2$ ) on days 1, 3, and 5 . Tumors were collected on day 11 for histological analysis. Paraffin sections of tumor tissue were stained using anti-Hexon, anti-TGF- $\beta 1$, and anti-TGF- $\beta 2$ antibodies. c A TUNEL assay was performed on tissue sections to quantify apoptotic cell death, as described in the "Materials and methods" section. The percentage of TUNEL-positive cells was determined by counting the TUNEL-positive cells under 10 noncontinuous low-power fields. $\mathbf{d}$ TGF- $\beta 1$ or - $\beta 2$ downregulation can cause both NOX4-mediated ROS production and a reduction in Smad complexes (phospho-Smad2, 3 with Smad4) that translocate to the nucleus to bind to gene promoters for the expression of Trx/GSTM1. ROS triggered by decreased Akt activity can dissociate Trx or GSTM1 from ASK1-Trx and ASK1-GSTM1 complexes. ASK1 activation is also related to the reduction in Trx and GSTM1 gene expression, which results from decreased transcriptional activity of the Smad complex. In these ways, ASK1 was fully activated and induced cytotoxic tumor cell death via p38/ JNK activation and induction of ER stress, which stimulated the escalation of ASK1 activation by completion of a sustained positive feedback loop circuit. Circled numbers indicate the chronological order of the signaling events leading to escalated cancer cell death

intensity of activation. p38 mitogen-activated protein kinase was first known to be activated in response to TGF- $\beta$ treatment but not to TGF- $\beta$ downregulation ${ }^{67-70}$. In this case, TGF- $\beta$ suppressed growth in normal epithelial cells, thereby acting in a cytostatic role to prevent the generation of hyperproliferative disorders such as cancer ${ }^{1}$. However, with an accumulation of genetic and epigenetic alterations in tumor cells, its function switches to the promotion of a pro-invasive and pro-metastatic phenotype, accompanied by a progressive increase in locally secreted TGF- $\beta$ levels ${ }^{1}$. Owing to the dichotomous nature of TGF- $\beta$ acting as both a tumor suppressor and a significant stimulator of tumor progression, depending on the cell types in which it is activated, TGF- $\beta$ treatment or TGF- $\beta$ downregulation can be used to induce normal cell death or cancer cell death, respectively, of the epithelium through the same signaling pathway. In contrast to TGF- $\beta$ downregulation in cancer cells, even excessive TGF- $\beta$ treatment in the same cancer cells did not show any cancer cell death. Instead, TGF- $\beta$ downregulation was accompanied by weak activation of p38 and a few antiapoptotic molecules, reflecting a low sensitivity of cancer cells with higher levels of TGF- $\beta$ to TGF- $\beta$ treatment and again verifying a role of TGF- $\beta$ as a regulator of cancer cell progression ${ }^{58,71}$. Our results indicating that the differential p38 activation of TGF- $\beta$ downregulation and TGF- $\beta$ treatment is correlated with cellular destination are also similar to our previous reports that a biphasic role exists depending on the activation level of p38, that is, cell death with strong p38 activation or cell survival with weak p38 activation after treatment with anticancer agents, such as curcumin or tumor necrosis factor-related apoptosis-inducing ligand $\mathrm{d}^{72,73}$.

Interestingly, TAK1, which is known to be activated by TGF- $\beta$ family ligands ${ }^{23}$ and is thought to be a survival signal, did not contribute to the effects observed in this study (data not shown). Rather, we identified ASK1induced JNK/p-38 as the primary apoptosis signal originating from TGF- $\beta$ downregulation-induced Akt inactivation. However, it is still difficult to determine whether ASK1-p38/JNK is the only specific key signaling molecule in the SAPK pathway.

Another finding from this study was that the downregulation of TGF- $\beta$ in cancer cells could promote ROS generation depending on the cancer cell type. TGF- $\beta 1$ downregulation in A375 cells enhanced ROS in a NOX4dependent manner, whereas TGF- $\beta 2$ downregulation in A37 5 cells or TGF- $\beta 1$ or $-\beta 2$ downregulation in HPAC seemed to generate few ROS in a non-NOX4-dependent manner. The increase in ROS in A375 cells after TGF- $\beta 1$ downregulation was likely triggered by a decrease in tumor-promoting non-canonical Akt activation ${ }^{25,74}$ mediated by NOX4 expression rather than by the canonical Smad signaling pathway, which is also known to have a tumor-promoting role ${ }^{75}$. The cellular redox state is determined by ROS production and elimination under different conditions. (A) Under normal conditions, cancer cells maintain redox homeostasis by balancing ROS production and elimination. (B) Under metabolic stress, redox homeostasis is damaged owing to enhanced ROS production and decreased ROS elimination ${ }^{76}$. Based on these two possible environments, lower levels of ROS can oxidize the disulfide bridges in Akt, leading to the association of Akt with PP2A and thus short-term activation of $\mathrm{Akt}^{77}$. However, because higher levels of ROS correspond to an overall decrease in cell survival potential, including Akt inactivation, resulting in severe damage to survival-death homeostasis, ROS are likely to be an irreversible sign of cell death, exacerbating ASK1-induced cell death through enhanced ER stress conditions.

Taken together, our findings demonstrated that the downregulation of TGF- $\beta$ via shRNAs induced tumor cell 
death, an effect that was driven by ASK1-SAPK axis signaling cascade regulated by a positive feedback circuit triggered by Akt inactivation/NOX4 increase-derived ROS-mediated ER stress (A375 cells) or tumor cell death driven by direct ASK1-SAPK axis signaling cascade (HPAC cells). For the goal of cancer treatment, it would be desirable to retain the TGF- $\beta$-mediated stimulation of apoptosis in tumor cells but inhibit the cell-autonomous and non-cell-autonomous activities of TGF- $\beta^{8}$. In light of this viewpoint, downregulation of TGF- $\beta$ rather than knockout might result in a more effective therapeutic regimen. However, it is challenging to predict whether the blockade of TGF- $\beta$ with inhibitors would be sufficient to block the tumor-promoting effects of TGF- $\beta$ without affecting its tumor-suppressive functions ${ }^{78}$. Nevertheless, our data provide an underlying mechanism of how TGF- $\beta$ downregulation induces cancer cell death.

\section{Acknowledgements}

This research was supported by the Korea Drug Development Fund funded by the Ministry of Science, Information and Communication Technology, and Future Planning, Ministry of Trade, Industry, and Energy, and Ministry of Health and Welfare (KDDF-201606-17, Republic of Korea), as well as by the Basic Science Research Program through the National Research Foundation of Korea (NRF) funded by the Ministry of Education (NRF-2016R1D1A1B03930934). Z.H. and J.L. were supported by the Brain Korea 21 Plus Project for Medical Science (Yonsei University, College of Medicine, Seoul, Republic of Korea).

\section{Author details}

'Institute for Cancer Research, Yonsei University College of Medicine, Seoul, Korea. ${ }^{2}$ Department of Oncology, Affiliated Hospital of Yanbian University, Yanji, Jilin Province, P.R. China. ${ }^{3}$ Severance Biomedical Science Institute, Yonsei University College of Medicine, Seoul, Korea. ${ }^{4}$ Department of Internal Medicine, Yonsei University College of Medicine, Seoul, Korea

\section{Conflict of interest}

The authors declare that they have no conflict of interest.

\section{Publisher's note}

Springer Nature remains neutral with regard to jurisdictional claims in published maps and institutional affiliations.

Supplementary information accompanies this paper at https://doi.org/ 10.1038/s12276-018-0189-8.

Received: 7 January 2018 Revised: 6 September 2018 Accepted: 11 September 2018.

Published online: 6 December 2018

\section{References}

1. Papageorgis, P. TGFbeta signaling in tumor initiation, epithelial-tomesenchymal transition, and metastasis. J. Oncol. 2015, 587193 (2015).

2. Massague, J. TGF-beta signal transduction. Annu. Rev. Biochem. 67, 753-791 (1998).

3. Lebrun, J. J. The dual role of TGFbeta in human cancer: from tumor suppression to cancer metastasis. ISRN Mol. Biol. 2012, 381428 (2012).

4. Wakefield, L. M. \& Hill, C. S. Beyond TGFbeta: roles of other TGFbeta superfamily members in cancer. Nat. Rev. Cancer 13, 328-341 (2013).

5. Siegel, P. M. \& Massague, J. Cytostatic and apoptotic actions of TGF-beta in homeostasis and cancer. Nat. Rev. Cancer 3, 807-821 (2003).
6. Xu, J., Lamouille, S. \& Derynck, R. TGF-beta-induced epithelial to mesenchymal transition. Cell Res. 19, 156-172 (2009).

7. Dumont, N. \& Arteaga, C. L. Targeting the TGF beta signaling network in human neoplasia. Cancer Cell 3, 531-536 (2003).

8. Derynck, R., Akhurst, R. J. \& Balmain, A. TGF-beta signaling in tumor suppression and cancer progression. Nat. Genet. 29, 117-129 (2001).

9. Jakowlew, S. B. Transforming growth factor-beta in cancer and metastasis. Cancer Metastasis Rev. 25, 435-457 (2006).

10. Neuzillet, C. et al. Targeting the TGFbeta pathway for cancer therapy. Pharmacol. Ther. 147, 22-31 (2015).

11. Massague, J. TGFbeta signalling in context. Nat. Rev. Mol. Cell Biol. 13, 616-630 (2012).

12. Wakefield, L. M. \& Roberts, A. B. TGF-beta signaling: positive and negative effects on tumorigenesis. Curr. Opin. Genet. Dev. 12, $22-29$ (2002).

13. Massague, J. TGFbeta in cancer. Cell 134, 215-230 (2008).

14. Huang, F. \& Chen, Y. G. Regulation of TGF-beta receptor activity. Cell Biosci. 2, 9 (2012).

15. Inman, G. J. Switching TGFbeta from a tumor suppressor to a tumor promoter. Curr. Opin. Genet. Dev. 21, 93-99 (2011).

16. Derynck, R. \& Zhang, Y. E. Smad-dependent and Smad-independent pathways in TGF-beta family signalling. Nature 425, 577-584 (2003).

17. Ross, S. \& Hill, C. S. How the Smads regulate transcription. Int. J. Biochem. Cell Biol. 40, 383-408 (2008).

18. Massague, J., Seoane, J. \& Wotton, D. Smad transcription factors. Genes Dev. 19, 2783-2810 (2005)

19. Jaffe, A. B. \& Hall, A. Rho GTPases: biochemistry and biology. Annu. Rev. Cell Dev. Biol. 21, 247-269 (2005).

20. Bakin, A. V., Tomlinson, A. K, Bhowmick, N. A., Moses, H. L. \& Arteaga, C. L. Phosphatidylinositol 3-kinase function is required for transforming growth factor beta-mediated epithelial to mesenchymal transition and cell migration. J. Biol. Chem. 275, 36803-36810 (2000).

21. Shin, I., Bakin, A. V., Rodeck, U., Brunet, A. \& Arteaga, C. L. Transforming growth factor beta enhances epithelial cell survival via Akt-dependent regulation of FKHRL1. Mol. Biol. Cell 12, 3328-3339 (2001).

22. Wang, S. E. The functional crosstalk between HER2 tyrosine kinase and TGFbeta signaling in breast cancer malignancy. J. Signal Transduct. 2011, 804236 (2011).

23. Yamaguchi, $K$. et al. Identification of a member of the MAPKKK family as a potential mediator of TGF-beta signal transduction. Science 270, 2008-2011 (1995).

24. Kim, S. I., Kwak, J. H., Wang, L. \& Choi, M. E. Protein phosphatase 2A is a negative regulator of transforming growth factor-beta1-induced TAK1 activation in mesangial cells. J. Biol. Chem. 283, 10753-10763 (2008).

25. Zhang, Y. E. Non-Smad pathways in TGF-beta signaling. Cell Res. 19, 128-139 (2009).

26. Mu, Y., Gudey, S. K. \& Landstrom, M. Non-Smad signaling pathways. Cell Tissue Res. 347, 11-20 (2012)

27. Ichijo, H. et al. Induction of apoptosis by ASK1, a mammalian MAPKKK that activates SAPK/JNK and p38 signaling pathways. Science 275, 90-94 (1997).

28. Chen, Z. et al. ASK1 mediates apoptotic cell death induced by genotoxic stress. Oncogene 18, 173-180 (1999).

29. Roulston, A., Reinhard, C., Amiri, P. \& Williams, L. T. Early activation of c-Jun Nterminal kinase and p38 kinase regulate cell survival in response to tumor necrosis factor alpha. J. Biol. Chem. 273, 10232-10239 (1998).

30. Kim, J. et al. HSP27 modulates survival signaling networks in cells treated with curcumin and TRAlL. Cell. Signal. 24, 1444-1452 (2012).

31. Hsieh, C. C. \& Papaconstantinou, J. Thioredoxin-ASK1 complex levels regulate ROS-mediated p38 MAPK pathway activity in livers of aged and long-lived Snell dwarf mice. FASEB J. 20, 259-268 (2006).

32. Matsukawa, J., Matsuzawa, A., Takeda, K. \& Ichijo, H. The ASK1-MAP kinase cascades in mammalian stress response. J. Biochem. 136, 261-265 (2004).

33. Tobiume, K. et al. ASK1 is required for sustained activations of JNK/p38 MAP kinases and apoptosis. EMBO Rep. 2, 222-228 (2001).

34. Hayyan, M., Hashim, M. A. \& AlNashef, I. M. Superoxide ion: generation and chemical implications. Chem. Rev. 116, 3029-3085 (2016).

35. Muller, F. The nature and mechanism of superoxide production by the electron transport chain: Its relevance to aging. J. Am. Aging Assoc. 23, 227-253 (2000).

36. Liou, G. Y. \& Storz, P. Reactive oxygen species in cancer. Free Radic. Res. 44 479-496 (2010) 
37. Burdon, R. H., Gill, V. \& Rice-Evans, C. Oxidative stress and tumour cell proliferation. Free Radic. Res. Commun. 11, 65-76 (1990),

38. Qu, K. et al. Emodin induces human T cell apoptosis in vitro by ROS-mediated endoplasmic reticulum stress and mitochondrial dysfunction. Acta Pharmacol. Sin. 34, 1217-1228 (2013).

39. Malhotra, J. D. \& Kaufman, R. J. Endoplasmic reticulum stress and oxidative stress: a vicious cycle or a double-edged sword? Antioxid. Redox Signal. 9, 2277-2293 (2007).

40. Zeeshan, H. M., Lee, G. H., Kim, H. R. \& Chae, H. J. Endoplasmic reticulum stress and associated ROS. Int. J. Mol. Sci. 17, 327 (2016).

41. Hetz, C., Martinon, F., Rodriguez, D. \& Glimcher, L. H. The unfolded protein response: integrating stress signals through the stress sensor IRE1alpha. Physiol. Rev. 91, 1219-1243 (2011).

42. Powis, G., Mustacich, D. \& Coon, A. The role of the redox protein thioredoxin in cell growth and cancer. Free Radic. Biol. Med. 29, 312-322 (2000).

43. Saitoh, M. et al. Mammalian thioredoxin is a direct inhibitor of apoptosis signal-regulating kinase (ASK) 1. EMBO J. 17, 2596-2606 (1998).

44. Fujino, G., Noguchi, T., Takeda, K. \& Ichijo, H. Thioredoxin and protein kinases in redox signaling. Semin. Cancer Biol. 16, 427-435 (2006).

45. Cho, S. G. et al. Glutathione S-transferase mu modulates the stress-activated signals by suppressing apoptosis signal-regulating kinase 1. J. Biol. Chem. 276, 12749-12755 (2001).

46. Oh, S. et al. Transforming growth factor-beta gene silencing using adenovirus expressing TGF-beta1 or TGF-beta2 shRNA. Cancer Gene. Ther. 20, 94-100 (2013).

47. Pardali, K. \& Moustakas, A. Actions of TGF-beta as tumor suppressor and prometastatic factor in human cancer. Biochim. Biophys. Acta 1775, 21-62 (2007).

48. Son, Y., Kim, S., Chung, H. T. \& Pae, H. O. Reactive oxygen species in the activation of MAP kinases. Methods Enzymol. 528, 27-48 (2013).

49. McCubrey, J. A., Lahair, M. M. \& Franklin, R. A. Reactive oxygen species-induced activation of the MAP kinase signaling pathways. Antioxid. Redox Signal. 8, 1775-1789 (2006).

50. Son, Y. et al. Mitogen-activated protein kinases and reactive oxygen species: how can ROS activate MAPK pathways? J. Signal Transduct. 2011, 792639 (2011).

51. Zafarullah, M., Li, W. Q., Sylvester, J. \& Ahmad, M. Molecular mechanisms of Nacetylcysteine actions. Cell. Mol. Life Sci. 60, 6-20 (2003).

52. Santos, C. X., Tanaka, L. Y., Wosniak, J. \& Laurindo, F. R. Mechanisms and implications of reactive oxygen species generation during the unfolded protein response: roles of endoplasmic reticulum oxidoreductases, mitochondrial electron transport, and NADPH oxidase. Antioxid. Redox Signal. 11, 2409-2427 (2009)

53. Galan, M. et al. Mechanism of endoplasmic reticulum stress-induced vascular endothelial dysfunction. Biochim. Biophys. Acta 1843, 1063-1075 (2014).

54. Heldin, C. H., Miyazono, K. \& ten Dijke, P. TGF-beta signalling from cell membrane to nucleus through SMAD proteins. Nature 390, 465-471 (1997).

55. Tuzun, S., Yucel, A. F., Pergel, A., Kemik, A. S. \& Kemik, O. Lipid peroxidation and transforming growth factor-beta1 levels in gastric cancer at pathologic stages. Balk. Med. J. 29, 273-276 (2012).

56. Dropmann, A. et al. TGF-beta1 and TGF-beta2 abundance in liver diseases of mice and men. Oncotarget 7, 19499-19518 (2016).

57. Friess, $\mathrm{H}$. et al. Enhanced expression of the type II transforming growth factor beta receptor in human pancreatic cancer cells without alteration of type III receptor expression. Cancer Res. 53, 2704-2707 (1993).
58. Drabsch, Y. \& ten Dijke, P. TGF-beta signalling and its role in cancer progression and metastasis. Cancer Metastas-. Rev. 31, 553-568 (2012).

59. Begas, P., Liedgens, L., Moseler, A., Meyer, A. J. \& Deponte, M. Glutaredoxin catalysis requires two distinct glutathione interaction sites. Nat. Commun. $\mathbf{8}$, 14835 (2017).

60. Song, J. J. et al. Role of glutaredoxin in metabolic oxidative stress. Glutaredoxin as a sensor of oxidative stress mediated by $\mathrm{H}_{2} \mathrm{O} 2$. J. Biol. Chem. 277, 46566-46575 (2002).

61. Rhee, S. G., Woo, H. A., Kil, I. S. \& Bae, S. H. Peroxiredoxin functions as a peroxidase and a regulator and sensor of local peroxides. J. Biol. Chem. 287, 4403-4410 (2012).

62. Barranco-Medina, S., Lazaro, J. J. \& Dietz, K. J. The oligomeric conformation of peroxiredoxins links redox state to function. FEBS Lett. 583, 1809-1816 (2009).

63. Ip, Y. T. \& Davis, R. J. Signal transduction by the c-Jun N-terminal kinase (JNK)from inflammation to development. Curr. Opin. Cell Biol. 10, $205-219$ (1998).

64. Turjanski, A. G., Vaque, J. P. \& Gutkind, J. S. MAP kinases and the control of nuclear events. Oncogene 26, 3240-3253 (2007).

65. Wagner, E. F. \& Nebreda, A. R. Signal integration by JNK and p38 MAPK pathways in cancer development. Nat. Rev. Cancer 9, 537-549 (2009).

66. Guo, Y. L., Baysal, K., Kang, B., Yang, L. J. \& Williamson, J. R. Correlation between sustained c-Jun $\mathrm{N}$-terminal protein kinase activation and apoptosis induced by tumor necrosis factor-alpha in rat mesangial cells. J. Biol. Chem. 273, 4027-4034 (1998).

67. Hanafusa, $H$. et al. Involvement of the p38 mitogen-activated protein kinase pathway in transforming growth factor-beta-induced gene expression. J. Biol. Chem. 274, 27161-27167 (1999).

68. Hartsough, M. T. \& Mulder, K. M. Transforming growth factor beta activation of p44mapk in proliferating cultures of epithelial cells. J. Biol. Chem. 270, 7117-7124 (1995).

69. Engel, M. E., McDonnell, M. A., Law, B. K. \& Moses, H. L. Interdependent SMAD and JNK signaling in transforming growth factor-beta-mediated transcription. J. Biol. Chem. 274, 37413-37420 (1999).

70. Yu, L., Hebert, M. C. \& Zhang, Y. E. TGF-beta receptor-activated p38 MAP kinase mediates Smad-independent TGF-beta responses. EMBO J. 21, 3749-3759 (2002).

71. Korpal, M. \& Kang, Y. Targeting the transforming growth factor-beta signalling pathway in metastatic cancer. Eur. J. Cancer 46, 1232-1240 (2010).

72. Kang, D., Park, W., Lee, S., Kim, J. H. \& Song, J. J. Crosstalk from survival to necrotic death coexists in DU-145 cells by curcumin treatment. Cell. Signal. 25, 1288-1300 (2013).

73. Kim, J., Kang, D., Sun, B. K., Kim, J. H. \& Song, J. J. TRAlL/MEKK4/p38/HSP27/Akt survival network is biphasically modulated by the Src/CIN85/C-Cbl complex. Cell. Signal. 25, 372-379 (2013).

74. Yoo, Y. A., Kim, Y. H., Kim, J. S. \& Seo, J. H. The functional implications of Akt activity and TGF-beta signaling in tamoxifen-resistant breast cancer. Biochim. Biophys. Acta 1783, 438-447 (2008).

75. Hernanda, P. Y. et al. SMAD4 exerts a tumor-promoting role in hepatocellular carcinoma. Oncogene 34, 5055-5068 (2015).

76. Zhao, Y. et al. ROS signaling under metabolic stress: cross-talk between AMPK and AKT pathway. Mol. Cancer 16, 79 (2017).

77. Zhang, J. et al. ROS and ROS-mediated cellular signaling. Oxid. Med. Cell Longev. 2016, 4350965 (2016).

78. Syed, V. TGF-beta signaling in cancer. J. Cell. Biochem. 117, 1279-1287 (2016) 